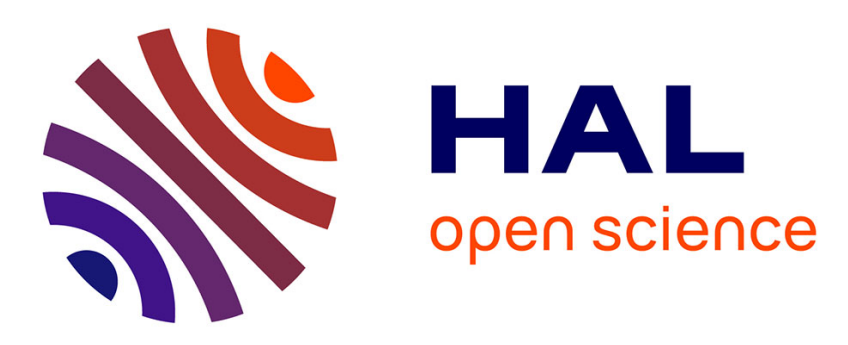

\title{
Are social and environmental clauses a tool for favoritism? Analysis of French public procurement contracts *
}

François Maréchal, Pierre-Henri Morand

\section{- To cite this version:}

François Maréchal, Pierre-Henri Morand. Are social and environmental clauses a tool for favoritism? Analysis of French public procurement contracts *. European Journal of Political Economy, In press. hal-03418572

\author{
HAL Id: hal-03418572 \\ https://hal.science/hal-03418572
}

Submitted on 7 Nov 2021

HAL is a multi-disciplinary open access archive for the deposit and dissemination of scientific research documents, whether they are published or not. The documents may come from teaching and research institutions in France or abroad, or from public or private research centers.
L'archive ouverte pluridisciplinaire HAL, est destinée au dépôt et à la diffusion de documents scientifiques de niveau recherche, publiés ou non, émanant des établissements d'enseignement et de recherche français ou étrangers, des laboratoires publics ou privés. 


\title{
Are social and environmental clauses a tool for favoritism? Analysis of French public procurement contracts*
}

\author{
François Maréchal ${ }^{\dagger}$ and Pierre-Henri Morand ${ }^{\ddagger}$
}

October 28, 2021

\begin{abstract}
This article analyzes the use of social and environmental clauses in public procurement contracts. After describing the current French legal context, it shows how a mechanism design approach can explain the factors that theoretically justify such practices, potentially including favoritism and rent-seeking. An empirical analysis is then carried out on the French public procurement data set for the year 2017. It illustrates the weight of political preferences in the choice to resort to social clauses and the weight of the preferences of the local chief executive to explain the use of environmental clauses. It also highlights that social and environmental clauses do not seem to be used as a tool for favoritism.
\end{abstract}

Keywords: Public procurement; social clauses; environmental clauses; favoritism

JEL: D44; D82; H57; Q01; Q28

*This research is part of the DeCoMaP project - Grant ANR-19-CE38-0004. The authors are very grateful to Professor Toke Aidt, Editor, and two anonymous referees whose comments and suggestions allowed us to substantially improve the article. The usual disclaimer applies.

${ }^{\dagger}$ CRESE EA3190, Univ. Bourgogne Franche-Comté, francois.marechal@univ-fcomte.fr

${ }^{\ddagger}$ LBNC EA3788, University of Avignon, pierre-henri.morand@univ-avignon.fr 


\section{Introduction}

Sustainable Public Procurement (SPP) is a process by which public authorities seek to achieve the appropriate balance between the three pillars of sustainable development - economic, social, and environmental - when procuring goods, services, or works at all stages of a project. Many public authorities in the world are implementing Green Public Procurement (GPP) as part of a broader approach to sustainability in their purchasing, which also addresses economic and social issues. 1 The idea of entrusting to the public commissioning of social policy objectives is older. McCrudden [2007], for example, relates past experiences that punctuate public authority contracts around the world: minimum wage clauses as early as 1891 in the United Kingdom and 1899 in France, social integration clauses from 1938 in the USA for the blind, etc.

An immediate question to ask is whether public procurement works as an effective policy instrument to achieve these issues. The arguments to settle this debate can be of two kinds:

Firstly, it is a question of evaluating the potential benefits of such public procurement rules on environmental or social aspects. Investigating e.g. the extent to which procurement policies actually improve the environment is not such an easy task since it depends on the market response to GPP procedures (see e.g. Marron 1997] and Lundberg et al. [2012]). The same is true for social aspects since a non partial analysis must be conducted. In this paper,

\footnotetext{
${ }^{1}$ The current EU Procurement Directives (2014) provide new opportunities for promoting social sustainability through the public procurement process. In the same vein, as early as 2004, the French Public Procurement Code allowed social and environmental considerations to be taken into account in the procurement process. This approach was extended in the 2006 version of the Code des marchés publics. Ordinance 2015-899 of 23 July 2015 allows for closer consideration of the concerns of both the public and the private sector. This enables buyers to insert criteria and social and environmental clauses into public procurement or concession agreements, with, for example, the option of reserving their contracts for operators in economic sectors employing at least $50 \%$ disabled or disadvantaged people. Similar changes in the regulation of public procurement can be observed in most developed countries. World Trade Organization (WTO) Agreement on Public Procurement (APP), for example, which in its last revision (2012) that entered into force in April 2014, expressly envisages the inclusion of environmental aspects in technical specifications (art. X.6) and as evaluation criteria (art. X.9); or the United Nations Commission on International Trade Law (UNCITRAL) Model Law on Public Procurement, approved 1 July 2011 integrates the possibility of choosing contractors based on their ecologic characteristics.
} 
we do not address the issue of evaluating the potential benefits of such clauses on environmental or social aspects.2

The second argument does not address the effectiveness of environmental or social clauses but rather the "sincerity" of the objective pursued. Indeed, there is a fine line between targeted procurement (i.e., favoring a firm because of the social or environmental benefits it provides) and favoritism (i.e., favoring a firm for less avowed reasons). In this article, using a political economy approach where procurement policy is delegated to elected representatives or bureaucrats (public buyers), we analyze the reasons for the use of social or environmental (hereafter S.E.) clauses in public procurement contracts. In particular, what does the use of such clauses reveal about the preferences of public buyers? May these clauses being used as a tool for favoritism?

We first try to answer this question from a theoretical point of view. After determining the main properties of the public buyer's objective function, we highlight the benefits of including S.E. clauses in different benchmark cases. We also compare the optimal procedures from the point of view of social welfare and from the point of view of the public buyer to whom the implementation of the procedure is delegated. In particular, using the framework of the theoretical mechanism design literature, we derive the conditions under which the clauses chosen by the public buyer also maximize the social welfare. Beside, we provide the concrete forms of these clauses (scoring rules, set-asides, discriminatory rules). However, we show that it is difficult to answer our question from a theoretical point of view, since the same type of clauses can be used to satisfy multiple objectives (reflection of the preferences of the median voter for a type of firm or for a level of S.E. quality, rent-seeking, bribes). So, the mere observation of S.E. clauses does not allow to infer the real motivations of a public buyer.

An empirical analysis is, therefore, required to explain what the use of clauses reveals about public buyer preferences. To do this, we use an original data set of 58,402 French public procurement contracts awarded in 2017, highlighting the marked diversity of practices for the inclusion of S.E. clauses. Then, restricting attention to a sub-sample of only the contracts awarded by the Departmental Councils, in order to study a homogeneous set of 4.378 markets and identify the political hue of these local authorities, we perform

\footnotetext{
${ }^{2}$ Therefore, we also do not address the question of whether social or environmental objectives would be better achieved with a clause or with other instruments such as laws, regulations, taxes, or subsidies.
} 
three series of econometric tests.

The first one explains the probability of having a social clause in departmental public procurement contracts. The second one explains the probability of having an environmental clause in these contracts. Our analysis highlights the diversity of objectives that may justify such clauses. Social clauses seem to reflect political preferences, as well as the proportion of individuals who can benefit from these clauses in the jurisdiction. If environmental clauses seem to be explained less by considerations of partisan politics (studied on a left/right axis), the weight of the environmentalist electorate on the local executive appears to be decisive for such clauses. From this analysis, we cannot reject the hypothesis that S.E. clauses simply reflect differences in the median voters preferences of the jurisdictions studied.

Then, using local buying as a proxy for favoritism, the third test analyzes whether S.E. clauses appear to be a significant factor in order to help a local firm to succeed. We find that the inclusion of S.E. clauses significantly decreases the likelihood of local purchasing in public procurement. This result suggests that the use of S.E. clauses can rather be explained by welfare consideration and political affiliation than by a favoritism of specific firms (and not at a specific category of firm). The risk of favoritism may, therefore, be through the various methods of awarding markets (choice of awarding method, degree of publicity of the call for tenders) and/or the lack of mandatory method to compute scoring rules.

This article is organized as follows. After a brief review of the related literature (Section 2), a theoretical analysis of the use of S.E. clauses is provided in Section 3. The empirical analysis is carried out in Section 4. Some conclusions are drawn in Section 5.

\section{Related literature}

Our article lies at the intersection of three literatures: environmental economics of public procurement, political economy of corruption and favoritism, and optimal discrimination in procurement.

The effect of GPP as a policy instrument is not evident and currently not extensively researched (see Cheng et al. 2018]). Pioneer in this field of research, Marron [1997] illustrates theoretically a crowding out effect: if marginal production costs are increasing with environmental quality, private market responses may counteract changes in government purchasing favoring 
environmentally superior products in procurement thus reducing policy effectiveness. It highlights the fact that judgments of public sector purchasing policies must also include the market reactions from private consumers and producers. Lundberg and Marklund [2013] or Lundberg et al. [2016], integrating more specifically the procurement mechanism, empirically illustrate that the potential for GPP to function as an objective effective instrument of environmental policy is limited, while Lindström et al. [2020] conclude that the Swedish 2006 GPP organic food policy is associated with a significant positive impact on organic agricultural land. In short, the effectiveness of public procurement as an environmental policy instrument will differ depending on factors such as product characteristics, market power, and price sensitivities of private and public consumers.

The effectiveness of social procurement policy has, to the best of our knowledge and as noted by Denny-Smith et al. [2020], not yet been studied ${ }^{3}$ Logically, the arguments mentioned in the previous paragraph can be transposed from the case of green to the case of social purchasing. However, there is no evidence that these policies are more or less effective.

Saussier and Tirole 2015], in a note to the Conseil d'Analyse Economique ${ }^{4}$ indicated as the very first recommendation to

"Recognize that the purpose of public procurement is above all to satisfy an identified need by achieving the best performance in terms of costs and services or functionalities expected. Charging public procurement to achieve social, environmental, or innovation objectives is ineffective."

Beyond questions of effectiveness, the authors point to a second issue related to the development of Sustainable Public Procurement policies:

"Taking into account various objectives increases the (everpresent) risk of favoritism."

This leads to a further consideration of the literature on the political economy of corruption. Implicit in the formulation of the authors is the idea that favoritism must be condemned per se. In a more general acceptation, favoritism may correspond to legal practices, but also, to varying degrees,

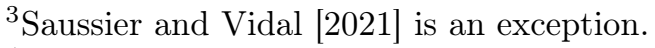

${ }^{4}$ Board of Economic Advisors to the French Prime Minister. 
to illegal practices that constitute the "dark side" of favoritism. As noted by Briquet [2020], the frontier between these two categories of practices is, moreover, uncertain and fluid, with several of them lying in the grey area of the margins of legality and the differences between licit and illicit behavior changing over time as a function of legal categorisations, and prevailing conceptions of public probity. For sake of simplicity, we will refer in the sequel to targeting for procurement policy which legally tends to favor a specific firm or category of firms. Favoritism will refer to illegal practices.

Among all the illegal practices, corruption and bribery have been extensively studied in procurement setting. As for example, Celentani and Ganuza 2002 consider a procurement agent also in charge of verifying delivered quality. In exchange for a bribe, he can allow an arbitrary firm to be awarded the realization of the project and to produce a quality level lower than that announced. Similarly, Burguet and Che 2004 study competitive procurement administered by a corrupt agent who is willing to manipulate his evaluation of contract proposals in exchange for bribes. In a mechanism design framework, Dastidar and Mukherjee [2014] theoretically analyze the effects of corruption in public procurement within a scoring-auction. A corrupt politician, who acts on behalf of the public sector, receives bribes from the winning bidder. They show that such corruption always leads to lower quality and lower price. These papers only consider the issue of corruption. Conversely, Hessami 2014 considers political rent creation in public procurement through the composition of the government budget in OECD countries, considering the public buyer as a rent-setter.

As noted by Lambsdorff 2002], "just like other forms of rent-seeking, corruption represents a way to escape the invisible hand of the market and influence policies to one's own advantage." However, there are diverging viewpoints on how far corruption differs from alternative forms of rent-seeking. Aidt 2016 proposes an helpful general taxonomy that clarifies the link between corruption and rent-seeking. Most of the corruption literature is concerned with situations where the corrupt agent gains and the influenceseeking activity represents a costless income transfer. At the other end, the rent-seeking literature may consider that resources are being employed by the firms in seeking a favor, which is assigned without any gain to the official who assigns it. Our definition of favoritism will encompass all actions between these two polar cases. Furthermore, there are different analytic approaches to corruption (see Aidt 2003]). In the following we will consider favoritism that arises when a benevolent principal delegates decision making power to 
a non-benevolent agent.

This article is also part of the literature on optimal targeting in public procurement. Targeting specific firms in public procurement is so often seen as a form of protectionism/favoritism. However, the literature has shown that it can also be the result of an optimal "sincere/honest" policy. Indeed, several arguments can explain the rationality of using such discriminatory policies.

A first argument is the presence of cost asymmetries between firms. Indeed, when two types of firms (domestic and foreign) compete and when there are cost advantages for foreign firms, McAfee and McMillan [1989] show that discrimination appears as the optimal policy of a public buyer interested in minimizing the expected cost of a procurement contract. In this case, it is optimal for the public buyer to discriminate in favor of domestic firms in order to stimulate competition.

A second argument is the presence of preference asymmetries, i.e., the procurement agent has a preference for one of the bidders. Note that the literature distinguishes between exogenous and endogenous preferences. In Branco [1994] and Vagstad [1995] e.g., the rationale for targeting is based on the assumption that the procurement agent puts more exogenous weight on domestic firms' rents (that derives from the agents' interest in domestic firms' profits) than on foreign firms' rents. ${ }^{5}$ Conversely, the preference asymmetry can also emerge endogenously. Indeed, in Laffont and Tirole [1991, the preference asymmetry of the procurement agent is an outcome of collusion between him and a bidder. In Celentani and Ganuza 2002, it is the result of a bribe demand by the procurement agent whereas it appears as an outcome of a bribery game in Burguet and Che 2004.

The conceptual difficulty in defining precisely the boundaries of what is legal and what is illegal, what is socially desirable or what practices need to be prevented, illustrates, in another way, the results achieved in this article. When observing specific practices in public procurement, it is difficult to know what is driving them.

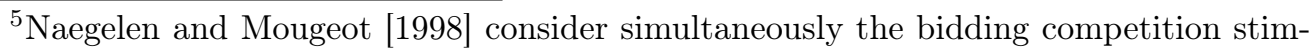
ulation effect and the effect of putting different weights on firms' rents in a model which also takes the social cost of public funds into account.
} 


\section{Theoretical analysis of the use of S.E. clauses}

In France, the Decree of 26 March 2016 reaffirmed the principle of awarding procurement contracts on the basis of the economically most advantageous tender. The question then arises as to the determination of the optimum procedure on the basis of this criterion. The theory of optimal auctions ( $\mathrm{My}-$ erson [1981]) provides a conceptual framework for assessing the optimality of the competitive tendering rules for the award of public contracts. In line with the literature on mechanism design, it aims to characterize the optimal selection rule (who wins?) and payment rule (who pays how much?) in situations where each firm has private information about its procurement costs. In this principal-agents setting, the principal and each firm vis-à-vis its potential competitors have only a priori beliefs about these costs. While this literature has focused mainly on determining the optimal rules in the "simple" framework where only the price criterion is taken into consideration and where the principal aims to buy at the lowest price, it also makes it possible to apprehend different situations, e.g., when the principal has intrinsic preferences for certain types of firms (cf. e.g., Branco [1994], Naegelen and Mougeot [1998], and Morand [2003]) or when the contract has a qualitative dimension that can vary the expected surplus (cf. e.g., Che 1993 and Asker and Cantillon [2008]).

Constructing the objective function within the conceptual framework of the mechanism design literature is not an obvious task. On the one hand, a distinction must be made between the objective that might be the one followed by a benevolent principal seeking to maximize the social surplus and the objective of a public buyer with potential private concerns. On the other hand, when considering the S.E. dimension of a public contract, three distinct and complementary aspects must be distinguished. Implicitly, they encompass the concepts of transformation policy and substitution policy mentioned in the SPP literature by Lundberg et al. 2016] 6

1. Firms can be differentiated by the level of surplus they generate if they are selected;

${ }^{6}$ As described by Lundberg et al. 2016], "a transformation policy is a situation in which the public sector aims at reducing environmental damage by creating incentives for brown suppliers to invest to become green. A substitution policy is here defined as a situation where the buyer substitutes a brown supplier with a green supplier without any changes in the suppliers' technology. In practice, one procurement process can include both types of policies." 
2. The social value of the profit made by the firms is not identical between firms of a different nature;

3. Each firm can increase the surplus produced by increasing the S.E. quality offered.

The comparison of the objective that would be pursued with the aim of maximizing the social surplus (Subsection 3.1) with that pursued by a public purchaser to whom the decision is delegated (Subsection 3.2) makes it possible to understand the interest of the delegation as well as the risks that the latter allows in terms of favoritism (Subsection 3.3). Then, Subsection 3.4 establishes that the same rules can be optimal from the point of view of social welfare and from the point of view of a public purchaser who pursues favoritism objectives. Therefore, it is not possible to distinguish between them as long as the information on the S.E. benefits of public procurement is known only to the public purchaser.

\subsection{The objective function of a benevolent principal}

In this subsection, let us first consider a benevolent principal. Obviously, his preferences are aligned with the median voter's wants. Formally, consider that two firms $i=s, t$ (one standard and one target) are competing for the award of a contract. We assume that the objective function of the benevolent principal includes the following three components:

Component 1 The degree $\alpha_{i} \in[0,1]$ to which the principal takes firm i's profit, $\Pi_{i}$, into account.7

Component 2 The principal assessment, $S_{i}$, of the fact that firm $i$ is carrying out the contract..$^{8}$

Component 3 The surplus, ${ }^{9} V\left(q_{i}\right)$, generated by the fact that the contract is carried out with a S.E. quality level $q_{i}$. This quality is assumed to be observable and verifiable.10 We assume that $V^{\prime}()>0,. V^{\prime \prime}()<0,. \lim _{q \rightarrow 0} V^{\prime}\left(q_{i}\right)=$ $+\infty$, and $\lim _{q \rightarrow+\infty} V^{\prime}\left(q_{i}\right)=0.11$

\footnotetext{
${ }^{7}$ Cf. e.g. Branco 1994, Naegelen and Mougeot 1998, and Morand 2003].

${ }^{8} \mathrm{Cf}$. Laffont and Tirole 1991.

${ }^{9}$ Cf. e.g. Che 1993, Asker and Cantillon 2008, and Nishimura 2015].

${ }^{10}$ When quality is unobservable, see e.g. Manelli and Vincent 1995 and Albano et al. 2017 .

${ }^{11}$ The last two assumptions ensure an interior solution.
} 
We also make the following assumptions on firms' costs and information:

Assumption 1 When choosing a level of S.E. quality $q_{i}$, firm $i$ incurs a cost $c\left(q_{i}, \theta_{i}\right)$, where $\theta_{i}$ represents its private efficiency parameter. The function $c$ is increasing in both $q_{i}$ and $\theta_{i}$ and satisfie $c_{q_{i} q_{i}} \geq 0, c_{q_{i} \theta_{i}}>0$, and $c_{q_{i} q_{i} \theta_{i}} \geq 0, \forall i=s, t$.

Assumption $2 \theta_{i}$ is privately observed by firm $i$ prior to bidding. However, it is common knowledge that $\theta_{i}$ is i.i.d. from a commonly known cumulative distribution function $F_{i}(\theta)$ on $\Theta_{i}=\left[\theta_{i}, \overline{\theta_{i}}\right]$. $F_{i}(\theta)$ has a continuous probability density function $f_{i}(\theta)$ that is positive on $\Theta_{i} . F_{i}($.$) has a monotone and$ increasing hazard rate. ${ }^{13}$

Let us denote $\theta=\left(\theta_{s}, \theta_{t}\right), F(\theta)=\prod_{i} F_{i}\left(\theta_{i}\right)$, and $\Theta=\prod_{i} \Theta_{i}$. Let us also denote $t_{i}$ as the expected payment received by firm $i$, and $x_{i}$ its probability of winning. Then, the expected social welfare (derived from the contract) can be written as

$$
\begin{gathered}
\mathbb{E}_{\Theta} W=\int_{\Theta} \sum_{i}\left[\left(S_{i}+V\left(q_{i}\right)\right) x_{i}-(1+\lambda) t_{i}\right. \\
\left.+\alpha_{i}\left(t_{i}-c\left(q_{i}, \theta_{i}\right) x_{i}\right)\right] d F(\Theta),
\end{gathered}
$$

where $\lambda$ represents the shadow cost of public funds. Implicit in this equation is the assumption that the benevolent principal has a perfect information on components 1,2 , and 3 . However, from a political economy point of view, at the local level, in specific markets, the benevolent principal cannot know with precision either $S, \alpha$, or $V$. Let us, in the sequel, assume that the benevolent principal cannot observe these components and has the following beliefs:

Assumption 3 Let $\tilde{S}_{i}, \tilde{V}()$ and $\tilde{\alpha}_{i}$ represent the beliefs of the uninformed benevolent principal.

\footnotetext{
${ }^{12}$ Subscripts denote partial derivatives.

${ }^{13} \mathrm{As}$ in a large part of the literature on procurement auctions, note that we consider a private value auction. However, firms may have both private and common values. If the common value is known, then only the private component of the value matters. For each firm, this component is linked e.g. to its own cost structure and the way the contract auctioned off fits with the other contracts that the firm may have. If the common value is unknown at the time of the bid (for example in the case of auctions for concessions or for certain works contracts), then the procurement auction should probably be though as an interdependent value auction.
} 
In practice, he will, therefore, delegate the implementation of public procurement to a local public buyer who has full information on the components. However, in return, the latter is able to pursue her own agenda.

\subsection{The public buyer's objective function}

Delegation makes room for favoritism as firms may try to influence the decision of the public buyer to favor their own benefits. As described by Lambsdorff 2002, this favoritism can take several forms:

"Seeking preferential treatment by public decision-makers includes a wide range of different actions. Imagine that a manager of a construction company considers engaging in rent-seeking. This may include such diverse activities as first, bribery in order to obtain a contract in public procurement, second, organizing a lobby aimed at increased spending for public construction, or third, campaigning jointly with other interest groups to increase public spending. [...] All of these activities are potentially beneficial to the construction company and may bring about competition for the rents as other companies or lobbies also try to capture them."

Taking up these concepts in our analytical framework leads us first of all to distinguish explicitly three levers of favoritism.

The first one is bribery. Thus, let us consider that the following component enters the public buyer's objective function:

Component 4 The potential bribe, equal to a fraction, $\gamma_{i} \geq 0$, of the payment of the contract, given by firm $i$ to the public buyer.14

Following the taxonomy of Aidt 2016], the case of pure corruption "refers to the case where competition for preferential treatment is such that the [public buyer] benefits from the influence-seeking expenses/activities in the way of a costless income transfer from the [firms] to the [public buyer]".

As documented, e.g., by Hessami [2014], the second lever refers to symmetric favoritism, which can be defined as follows:

\footnotetext{
${ }^{14}$ Cf. Dastidar and Mukherjee [2014].
} 
Definition 1 Symmetric favoritism appears when rent-seeking activities induce the public buyer to consider distorted social value without inducing any preferential treatment between competing firms. Thus, we have:

$$
\hat{S}_{t}+\hat{V}\left(q_{t}\right)+\hat{\alpha}_{t} \Pi_{t} \geq \hat{S}_{s}+\hat{V}\left(q_{s}\right)+\hat{\alpha}_{s} \Pi_{s}
$$

and

$$
S_{t}+V\left(q_{t}\right)+\alpha_{t} \Pi_{t} \geq S_{s}+V\left(q_{s}\right)+\alpha_{s} \Pi_{s},
$$

where $\Pi_{i}$ denotes firm i's profit.

The third lever refers to asymmetric favoritism, which can be defined as follows:

Definition 2 Asymmetric favoritism appears when rent-seeking activities induce the public buyer to consider distorted social value inducing a preferential treatment between competing firms. Thus, we have:

$$
\hat{S}_{t}+\hat{V}\left(q_{t}\right)+\hat{\alpha}_{t} \Pi_{t} \geq \hat{S}_{s}+\hat{V}\left(q_{s}\right)+\hat{\alpha}_{s} \Pi_{s}
$$

while

$$
S_{t}+V\left(q_{t}\right)+\alpha_{t} \Pi_{t}<S_{s}+V\left(q_{s}\right)+\alpha_{s} \Pi_{s} .
$$

All these rent-seeking activities can lead to social dead-weight losses, reducing the expected social welfare. However, the latter do not impact the public buyer's surplus.

The public buyer's delegated surplus can so be written as:

$$
\begin{aligned}
\mathbb{E}_{\Theta} D S= & \int_{\Theta} \sum_{i}\left[\left(\hat{S}_{i}+\hat{V}\left(q_{i}\right)\right) x_{i}-(1+\lambda) t_{i}\right. \\
& \left.+\hat{\alpha}_{i}\left(\left(1-\gamma_{i}\right) t_{i}-c\left(q_{i}, \theta_{i}\right) x_{i}\right)+\gamma_{i} t_{i}\right] d F(\Theta),
\end{aligned}
$$

Given the asymmetry of information on firms' efficiency, the public buyer will then seek to maximize this objective function subject to several constraints. Let us denote $\Pi_{i}\left(\tilde{\theta}_{i}, \theta_{i}\right)$ as the expected profit of firm $i$ announcing $\tilde{\theta}_{i}$ while the true parameter is $\theta_{i}$. Considering incentive compatibility constraints

$$
\Pi_{i}\left(\theta_{i}, \theta_{i}\right) \geq \Pi_{i}\left(\tilde{\theta}_{i}, \theta_{i}\right) \forall i \forall \tilde{\theta}_{i}, \theta_{i}
$$


participation constraints

$$
\Pi_{i}\left(\theta_{i}, \theta_{i}\right) \geq 0 \forall \tilde{\theta}_{i}, \theta_{i}
$$

and feasibility constraints

$$
\sum_{i} x_{i} \leq 1
$$

the problem can be easily solved using traditional methods (Myerson 1981 and Che [1993]).15 The expected delegated surplus of the public buyer can thus be rewritten as a function of the S.E. quality required for the project and the selection rule

$$
\begin{aligned}
\mathbb{E}_{\Theta} D S= & \int_{\Theta} \sum_{i} x_{i}\left[\left(\hat{S}_{i}+\hat{V}\left(q_{i}\right)\right)-\frac{1+\lambda-\gamma_{i}}{1-\gamma_{i}} c\left(q_{i}, \theta_{i}\right)\right. \\
& \left.-\left(\frac{1+\lambda-\gamma_{i}}{1-\gamma_{i}}-\hat{\alpha}_{i}\right) \frac{F_{i}\left(\theta_{i}\right)}{f_{i}\left(\theta_{i}\right)} c_{\theta}\left(q_{i}, \theta_{i}\right)\right] d F(\Theta) .
\end{aligned}
$$

Given its parameter $\theta_{i}$, firm $i$ is induced to choose an optimal quality

$$
q^{*}\left(\theta_{i}\right)=\underset{q_{i}}{\arg \max } \hat{V}\left(q_{i}\right)-J_{i}\left(q_{i}, \theta_{i}\right)
$$

with $J_{i}\left(q_{i}, \theta_{i}\right)=\frac{1+\lambda-\gamma_{i}}{1-\gamma_{i}} c_{i}\left(q_{i}, \theta_{i}\right)+\left(\frac{1+\lambda-\gamma_{i}}{1-\gamma_{i}}-\hat{\alpha}_{i}\right) \frac{F_{i}\left(\theta_{i}\right)}{f_{i}\left(\theta_{i}\right)} c_{i_{\theta}}\left(q_{i}, \theta_{i}\right)$.

Firm $t$ e.g. is awarded the contract if

$$
\hat{S}_{t}+\hat{V}\left(q^{*}\left(\theta_{t}\right)\right)-J_{t}\left(q^{*}\left(\theta_{t}\right), \theta_{t}\right)>\hat{S}_{s}+\hat{V}\left(q^{*}\left(\theta_{s}\right)\right)-J_{s}\left(q^{*}\left(\theta_{s}\right), \theta_{s}\right) \quad \forall t, s .
$$

and simultaneously

$$
\hat{S}_{t}+\hat{V}\left(q^{*}\left(\theta_{t}\right)\right)-J_{t}\left(q^{*}\left(\theta_{t}\right), \theta_{t}\right)>0
$$

\subsection{The value of delegation}

Let us highlight the value of delegation by means of examples and start from the simplest situation in which there is no social cost of public funds and the public purchaser is sincere about the amount of S.E. benefits expected. Furthermore, consider the case of a fixed S.E. quality $\left(V\left(q_{i}\right)=V\left(q_{j}\right) \forall q_{i}, q_{j}\right)$. Consider also a situation of pure corruption. In this simplified framework,

\footnotetext{
${ }^{15}$ See Appendix A.1 for some intermediate calculus.
} 
the objective function of the public buyer differs from that of a benevolent principal only in the possibilities of corruption that the delegation allows.

The benefits of delegation are obvious. With better information on the amount of S.E. benefits, the public purchaser can implement an appropriate selection rule. As bribes are a simple transfer of wealth from firms to the buyer, and the social cost of public funds being assumed to be zero, the gain from delegation increases with the degree of uncertainty about the amount of S.E. benefits, regardless of the potential for bribes. With a positive social cost of public funds, bribes become socially costly. A trade-off arises between, on the one hand, the gains in allocative efficiency linked to delegation to an informed public purchaser and, on the other hand, the costs linked to the corruption that delegation allows. As highlighted by Figure 1, this trade-off is logically more inclined towards delegation when the uncertainty about S.E. benefits are high, the potential for corruption is limited and the social cost of public funds is low ${ }^{16}$
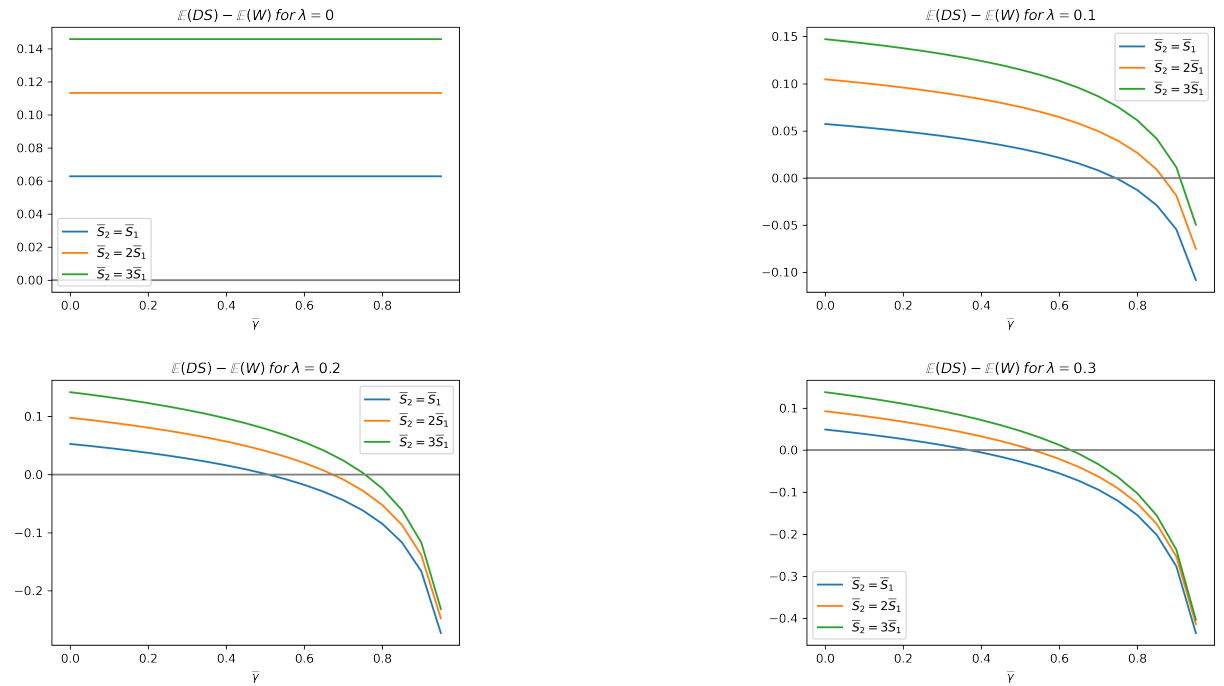

Figure 1: Expected gains from delegating the public procurement policy

Taking now into account the variable surplus generated by the fact that the contract can be carried out with a variable level of S.E. quality makes

\footnotetext{
${ }^{16}$ See Appendix A.2 for an exhaustive description of the simulation parameters. $\bar{S}_{i}$ corresponds to the upper bound of the distribution of $S_{i}$, uniform random variable whose realization is known only to the public buyer.
} 
this trade-off slightly more complex. Assume e.g that $S_{i}=S_{j}$ and $\alpha_{i}=\gamma_{i}=$ $\lambda=0$. This context is analyzed by Che 1993. Notice that the first-best quality level, $q^{F B}$, would maximize $V\left(q_{i}\right)-c\left(q_{i}, \theta_{i}\right)$. Hence, as shown by Che 1993, the optimal quality given by (4) is distorted downwards relative to the first-best level. ${ }^{17}$ The reason for obtaining a second-best quality level is that the selected firm obtains a rent in return for the disclosure of its private information. ${ }^{18}$ Achieving the optimal quality then requires the public purchaser to announce a bid evaluation rule that is different from her true preferences. In our example, notice that the optimal quality (from the point of view of the social welfare) can be implemented by a first score auction which proposes the scoring rule $S(q, c)=V(q)-q \theta-\Delta(q)$ with

$$
\Delta(q)=\int_{q^{*-1}(\bar{\theta})}^{q} \frac{F\left(q^{*^{-1}}(s)\right)}{f\left(q^{*^{-1}}(s)\right)} c_{q \theta}\left(s, q^{*^{-1}}(s)\right) d s
$$

If we consider now, following and adapting Dastidar and Mukherjee 2014], a delegation to a public buyer, who is bribed, with $\gamma_{t}=\gamma_{s}=\gamma$, then she chooses an optimal mechanism whereby she maximizes her own expected surplus

$$
V\left(q_{i}\right)-(1-\gamma) t_{i}
$$

Then, it is straightforward to show that she can implement the optimal mechanism by choosing the scoring rule

$$
S(q, c)=V(q)-(1-\gamma) q \theta-\Delta(q) .
$$

Therefore, when the public buyer is bribed, the scoring rule is slightly different (to the nearest $\gamma$ ) from the scoring rule that would implement the

\footnotetext{
${ }^{17}$ Asker and Cantillon 2008 extend this result to the case of a double asymmetry of information on the cost structure of firms (i.e., the public purchaser knows neither the marginal cost nor the fixed cost of the firms).

${ }^{18}$ In practice, however, the selection of firms does not take the form of an announcement of productivity parameters, but is based rather on announcements of price/quality pairs. Sinclair-Desgagné [1990 and Che 1993 show, in particular, that a procedure in which the public purchaser solicits proposals in terms of price and quality, with the winner making the deal at the price and quality level he has offered, makes it possible to achieve the optimal mechanism. Analyzing optimal mechanisms with one-dimensional quality and two-dimensional discrete types, Asker and Cantillon [2010] show that a scoring rule can implement a result close to the optimal mechanism. Asker and Cantillon 2008 also show (when the buyer can describe his preferences in terms of price-quality trade-off) that the use of a scoring rule is preferable to other methods such as a menu-auction, a beauty contest, or a price-only auction with minimum quality thresholds.
} 
optimal quality (without corruption) and induces an even lower level of quality. Compared to the situation described above, delegation induces an additional cost, related to the manipulation of the induced quality. As it reduces the expected quality and as quality is costly, it has in return a positive effect in terms of the social cost of public funds.

The general case, while more complex than the two previous illustrations, does not alter the general intuitions we have just illustrated: the benefits of delegating to a better-informed public buyer must be balanced against the costs of taking into account the parameters that reflect the public buyer's own preferences and not necessarily the preferences of the community for which he is supposed to act, as well as the impact on the expected S.E. quality. Furthermore, considering socially wasteful rent-seeking contests leads us to consider an additional social cost to delegation which further reduces the benefit of delegation. This additional cost may refer e.g. to corruption associated with transaction cost such that the value of the bribe for the public buyer is lower than the cost to the firm paying the bribe; or pure rent seeking in which influence-seeking competition for preferential treatment in the public procurement does not benefit the public buyer (see Aidt 2016 for a general discussion).

\subsection{Results and predictions}

The analysis of the optimal solution of a benevolent principal and the public buyer problem allows us to obtain several propositions and predictions. This highlights the fact that the use of S.E. clauses is both socially desirable in a large number of situations, but also potentially manipulable by the public buyer for the sake of favoritism. And the distinction between the two is usually not feasible.

Let us first describe in the two following propositions the situations where S.E. clauses achieve or not the maximum social welfare:

Proposition 1 S.E. clauses cannot be an optimal policy from a social welfare perspective when either the conditions described in point 1 or in point 2 are satisfied.

1. All the following conditions are simultaneously satisfied:

- The benevolent principal obtains the same surplus from contract completion regardless of the firm carrying out the contract, i.e., 
$S_{t}=S_{s} \forall t, s$.

- The contract has to be carried out with the same fixed and observable S.E. quality level $V\left(q_{t}\right)=V\left(q_{s}\right) \forall q_{t}, q_{s}$.

- The benevolent principal values firms' profits in a symmetrical way, i.e., $\alpha_{t}=\alpha_{s} \forall t, s$.

- The firms share the same cost-technology $c_{t}\left(q_{t}, \theta_{t}\right)=c_{s}\left(q_{s}, \theta_{s}\right) \forall t, s$.

- The distribution of efficiency parameters are the same, i.e, $F_{t}()=$. $F_{s}(.) \forall t, s$.

2. Firm $t$ can never be awarded the contract, i.e.,

$$
S_{t}+V\left(q^{*}\left(\underline{\theta_{t}}\right)\right)-J_{t}\left(q^{*}\left(\underline{\theta_{t}}\right), \underline{\theta_{t}}\right)<S_{s}+V\left(q^{*}\left(\overline{\theta_{s}}\right)\right)-J_{s}\left(q^{*}\left(\overline{\theta_{s}}\right), \overline{\theta_{s}}\right) \forall t, s .
$$

We find here in a more general framework the traditional results of McAfee and McMillan [1989 and Branco [1994]. If one of the two conditions of Proposition 1 is not met, different types of clauses may implement the optimal policy, as detailed in the following proposition.

\section{Proposition 2}

1. A clause which sets asides the contract for firm $t$ is an optimal policy from a social welfare perspective when awarding the contract to the the least efficient firm $t$ yields a greater welfare than the award of the contract to the most efficient firm s, i.e.,

$$
S_{t}+V\left(q^{*}\left(\overline{\theta_{t}}\right)\right)-J_{t}\left(q^{*}\left(\overline{\theta_{t}}\right), \overline{\theta_{t}}\right)>S_{s}+V\left(q^{*}\left(\underline{\theta_{s}}\right)\right)-J_{s}\left(q^{*}\left(\underline{\theta_{s}}\right), \underline{\theta_{s}}\right) \forall t, s .
$$

2. A clause which introduces a discriminatory rule in the competition for the award of the contract can be an optimal policy when

$$
S_{t}+V\left(q^{*}\left(\overline{\theta_{t}}\right)\right)-J_{t}\left(q^{*}\left(\overline{\theta_{t}}\right), \overline{\theta_{t}}\right)<S_{s}+V\left(q^{*}\left(\underline{\theta_{s}}\right)\right)-J_{s}\left(q^{*}\left(\underline{\theta_{s}}\right), \underline{\theta_{s}}\right) \forall t, s .
$$

Proposition 2 shows that clauses that set-aside the contract for a firm or introduce a discriminatory rule in the completion of the contract can be used as an optimal policy. It is worth noting that the use of clauses appears to be the rule and the absence of clauses the exception.

Naturally, as the implementation of public procurement is delegated to the public buyer, the procedures chosen are the one that are optimal from the point of view of the public buyer, which leads us to the following prediction: 
Prediction 1 The preferences of the public buyer may lead her to make more or less clauses than would be socially optimal.

Obviously, as symmetric favoritism does not imply any preferential treatment (between firms $t$ and $s$ ), the impact of this type of favoritism cannot be observed in the use of clauses, which from the point of view of optimal procedures, only serve to discriminate between firms:

Lemma 1 Symmetric favoritism can lead the public buyer to make a procurement that is not socially desirable. However, this does not involve the manipulation of clauses.

Under Assumption 3, only the public buyer knows the true value of the components. Only in very specific cases can favoritism be inferred by observing the chosen procedures:

\section{Prediction 2}

- If $V(),. \alpha_{i}$ and $S_{i}$ are common knowledge, then bribery can be detected simply by observing the use of a clause that generates too low a quality level

- If $V($.$) is private knowledge of the public buyer, a clause that intro-$ duces a scoring rule may indiscriminately reflect the implementation of an optimal policy or corruption. Therefore, bribery cannot be detected simply by observing the use of a clause.

To sum up, as described in the following proposition, the theoretical analysis does not make it possible to identify precisely the reasons for the use of S.E. clauses.

Proposition 3 The mere observation of S.E. clauses does not theoretically reveal the preferences of the public purchaser.

Indeed, the reasons for the use of such clauses may be "objective" (stimulation of competition, economic interest in selecting a target firm) or "assessed" by the public buyer (political assessment of the fact that a target firm is carrying out the contract, valuation of environmental quality, etc.). The use of clauses may also reflect favoritism which does not appear to be an optimal policy. In a world in which the public buyer's preferences are private information, the same procedure incorporating the same type of clause may theoretically translate different objectives. An empirical analysis is, therefore, required to explain what the use of clauses reveals about buyer preferences. 


\section{Empirical analysis}

Before implementing the three series of econometric tests that we perform, 19 let us first present some descriptive statistics about S.E. clauses in French procurement markets in 2017.

\subsection{S.E. clauses in French procurement markets in 2017: Some descriptive statistics}

The theoretical approach presented in Section 3 makes it possible to identify how the preferences of public purchasers condition the choice of the procedure to be implemented. Then, the analysis of the procedures actually used should in turn enable us to infer in part the underlying preferences of French public purchasers. The process of opening up essential public procurement data in France gives us very easy access to some huge data sets. Our empirical study focuses on these data sets. More precisely, the analysis is based on all the contracts (services and works) awarded in 2017 in France by all public purchasers (local authorities, decentralized state bodies, ministries, etc.) and which have been advertised in the official bulletin of public contracts (which can be freely retrieved via the API BOAMP.fr). ${ }^{20}$ This concerns 58,402 contracts. For each award, the characteristics of the buyer and the company selected are detailed, as well as the procedure (subject of the contract, procedure chosen, existence and details of any S.E. clauses, any weighting of the latter in the award rule, etc.). The additional political data are taken from the Répertoire National des Elus (RNE), making it possible to determine for the period under consideration the political affiliation, as well as individual characteristics of elected representatives. The external data used to characterize the departments under consideration, in demographic or economic terms, come from INSEE ${ }^{21}$ s open data.

While the use of S.E. clauses in public procurement is a long-standing practice, their increasing use is a recent trend in France. Following the survey carried out by the Economic Observatory of Public Procurement ${ }^{22}$ (OEAP), the share of public contracts with social clauses increased from

\footnotetext{
${ }^{19}$ All the material (data and Rmd files) for replication are available in Morand [2021].

${ }^{20}$ Bulletin Officiel des Annonces des Marchés Publics.

${ }^{21}$ The National Institute of Statistics and Economic Studies that collects, analyses, and disseminates information on the French economy and society.

${ }^{22}$ See Saussier and Tirole 2015.
} 
$1.9 \%$ to $6.1 \%$ between 2009 and 2013 (for contracts above $€ 90,000$ ). During the same period, the share of contracts with environmental clauses increased from $2.6 \%$ to $6.7 \%$. Our database shows that $4.1 \%$ of all public procurement contracts published on the BOAMP in 2017 contain social clauses and 8.5\% contain environmental clauses. If we consider the value and not the quantity, we can see in Table 1 that S.E. clauses are more used in markets with high value: Markets with environmental clauses represent $12.4 \%$ of the total value of markets (6.1\% for social clauses).

\begin{tabular}{|c|c|c|c|}
\hline & All contracts & Incl. env. clauses & Incl. soc. clauses \\
\hline Nbr. & 58402 & 4987 & 2382 \\
\hline Ratio & 100 & 8.5 & 4.1 \\
\hline Value (/B.€) & 67.41 & 8.34 & 4.11 \\
\hline Value (\%) & 100 & $\mathbf{1 2 . 4}$ & $\mathbf{6 . 1}$ \\
\hline Max (M.€) & 1390 & 256 & 256 \\
\hline Mean (M.€) & 1.15 & $\mathbf{1 . 6 7}$ & $\mathbf{1 . 7 3}$ \\
\hline Median (M.€) & 0.11 & 0.15 & 0.21 \\
\hline
\end{tabular}

Table 1: Public contracts with S.E. clauses

Behind these general statistics lies a great diversity of practices. This is true regarding the nature of the contracts that incorporate these clauses. As depicted by Table 2, social clauses are more frequent in works and services procurement contracts while environmental clauses are more used in office supplies procurement contracts. ${ }^{23}$

The use of S.E. clauses in public procurement also varies greatly depending on the kind of public purchaser. As depicted by Table 3 , purchases from "public sector body" represent $28 \%$ of all the procurement contracts but $57 \%$ of environmental clauses and $36 \%$ of social clauses while purchases from "local authority" represent $33 \%$ of all the markets but "only" represent $23 \%$ of environmental clauses and $26 \%$ of social clauses.

For the same category of public purchaser, geographical differences also exist. This is the case, for example, for purchases made only by the Departmental Councils (see Figure 2a, 2b) for which the geographical distribution of the frequency of use of these clauses shows up to fourfold differences.

\footnotetext{
${ }^{23}$ In the sequel, we will use a more detailed classification of the procurement contracts under consideration.
} 


\begin{tabular}{|c|c|c|c|}
\hline & All contracts & Incl. env. clauses & Incl. soc. clauses \\
\hline works (B.€) & 16.38 & 1.26 & 1.05 \\
\hline works (\%) & 100 & 7.6 & $\mathbf{6 . 4}$ \\
\hline office supplies (B.€) & 24.74 & 4.85 & 0.87 \\
\hline office supplies (\%) & 100 & $\mathbf{1 9 . 6}$ & 3.5 \\
\hline services (B.€) & 40.37 & 2.56 & 2.41 \\
\hline services (\%) & 100 & 6.3 & $\mathbf{5 . 9}$ \\
\hline
\end{tabular}

Table 2: The nature of contracts with S.E. clauses

\begin{tabular}{|c|c|c|c|}
\hline & All contracts & Incl. env. clauses & Incl. soc. clauses \\
\hline local auth. (\%) & 33.3 & 23.2 & 26.9 \\
\hline public sector body (\%) & $\mathbf{2 7 . 9}$ & $\mathbf{5 6 . 6}$ & $\mathbf{3 5 . 6}$ \\
\hline national auth. (\%) & 23.4 & 14 & 21.1 \\
\hline region. agency (\%) & 0.94 & 0.14 & 1.4 \\
\hline nation. agency (\%) & 0.18 & 0.33 & 0.14 \\
\hline
\end{tabular}

Table 3: Distribution of clauses according to purchasers

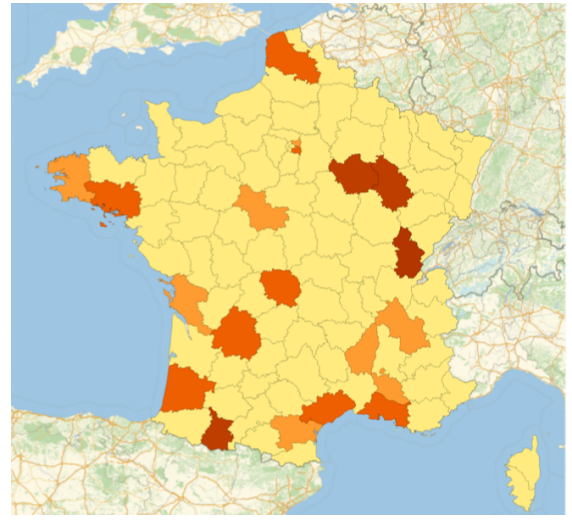

(a) Env. clauses.

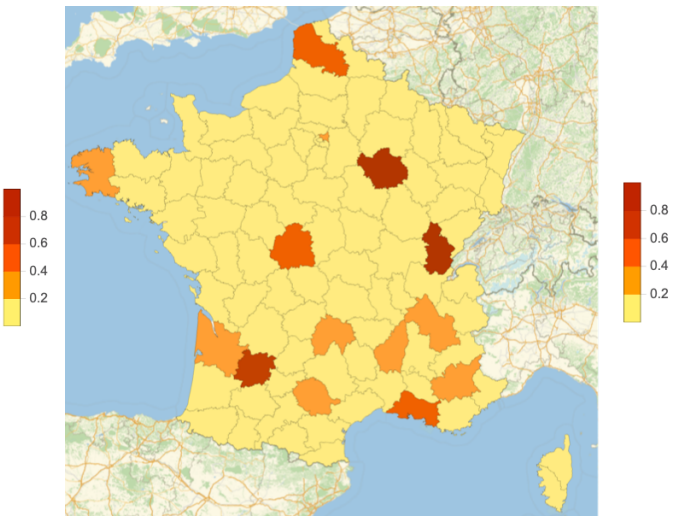

(b) Soc. clauses.

Figure 2: \% of clauses in Departmental Councils

French administrative architecture is quite complex. The $66 \%$ of contracts performed by local authorities in 2017 are at municipal, inter-municipal, departmental, and regional level. This reflects a variety of administrative 
jurisdictions. In the sequel, we choose to focus on a single administrative level: the Departmental Councils.

In France, the Departmental Council is the deliberative assembly of a department, elected by universal suffrage. The latest departmental assemblies elections took place in March 2015. In 2017, there were 97 Departmental Councils: one for each department (with specific status for Martinique, Guyana, and Paris). Managing a budget of around $€ 75$ billion, they represent one-third of the budget of all local authorities. Thus, due to their economic weight and the powers delegated to them, the Departmental Councils constitute a particularly interesting administrative level for studying their policies in terms of public procurement. Our database lists 4,378 fully documented contracts awarded by Departmental Councils. They correspond to a total of 7,048 lots awarded.

The previous theoretical analysis has shown the diversity of buyer preferences that can result (in an optimal mechanism design) in the inclusion of a clause. Similarly, the descriptive analysis of public procurement statistics in 2017 in France shows a very wide range of disparities in the use of S.E. clauses in practice: geographical heterogeneity, heterogeneity as to the nature of the public purchaser, as to the nature of the public contracts awarded. Discriminating between them in order to identify the underlying objective function of the public buyer is, therefore, an essentially empirical task.

In the remainder of this paper we will, therefore, proceed to the econometric analysis. After presenting our general econometric methodology and data, we first seek to identify the factors explaining the presence of social clauses in Departmental Council procurement contracts. Then, we test the probability of having an environmental clause in these contracts. Finally, using local purchasing as a proxy for favoritism, we test whether S.E. clauses appear to be a significant factor in order to help a local firm to succeed.

\subsection{What do S.E. clauses refer to for Departmental Coun- cils?}

The data available via the BOAMP API to analyze the public contracts awarded in 2017 only allow a partial analysis of the use of S.E. clauses. While BOAMP covers nearly $40 \%$ of all contracts awarded in France during this period, the archived data only provide limited information on the content of the contracts. In particular, the presence of a S.E. clause appears 
through a binary identification. However, we know nothing about the relative importance and nature of such a clause. In particular, it is unfortunately not possible to ascertain whether a clause is a set-aside clause or a discriminatory rule.

However, by cross-referencing these public procurement data with freely available external information, we can further investigate empirically the nature of the objective pursued by the public purchaser. In our empirical estimations, we investigate what motivates the clauses. We construct four binary variables.

- social clause (resp. environmental clause), which takes the value 1 if a Departmental Council included a social (resp. environmental) clause in a specific public procurement market; otherwise, they take the value 0 .

- social clause only (resp. environmental clause only), which takes the value 1 if a Departmental Council included only a social (resp. environmental) type clause in a specific public procurement market; otherwise, they take the value 0 .

Using Logit models, we test whether political attributes, departmental socio-economics attributes, and characteristics related to the very nature of the contract explain first the probability of having a social clause 4.2.1) and second that of having an environmental clauses 4.2.2.

For each of the regressions, we use a set of 7 explanatory variables, which we present, grouped by theme, below.

\section{Political attributes}

We describe the political context through 4 variables.

- Political Hue: political hue of the Departmental Council. This is a discrete variable restricted to a set of four values, representing the left-right political axis ( 0 for far-left, 1 for left, 2 for moderate, and 3 for right).

- Environmentalist Executive: This variable takes value 1 if an elected environmentalist on the Council has an executive function (vice-chair of the Council or task officer) and 0 otherwise. 
- Chief Executive Gender and Chief Executive Age: These two variables aim to capture the individual characteristics of the Chief Executive, through gender and age. Chief Executive Gender takes value 0 for male and 1 for female. Chief Executive Age is coded into two classes (one class below the median, 60 years, one class above).

\section{Population attributes}

Two variables describe the population of the department considered.

- Inequalities: reflects the level of inequality ratio $(D 90 / D 10)$ coded into 5 groups with equal range.

- Solidarity Income Support: corresponds to the proportion of individuals receiving the Solidarity Income Support (Revenue de Solidarité Active, R.S.A.) borne by the Departmental Councils and coded into 5 groups with equal range.

\section{Contracts attributes}

Finally, the specific characteristics of the procurement contracts under consideration are described by a polytomous variable. We use the Common Procurement Vocabulary ${ }^{24}$ code to group together markets for the same category of products or services in the following way.

- CPV: agri. \& cleaning services - energy refers to agricultural, forestry, horticultural, aquacultural and apicultural services (CPV 77), sewage, refuse, cleaning and environmental services (CPV 90), petroleum products, fuel, electricity and other sources of energy (CPV 09).

- CPV: building \& construction refers to construction structures and materials, auxiliary products to construction (except electric apparatus) (CPV 44), Construction work (CPV 45), Architectural, construction, engineering and inspection services (CPV 71).

\footnotetext{
${ }^{24}$ The common procurement vocabulary (CPV) establishes a single classification system for public procurement aimed at standardizing the references used by contracting authorities and entities to describe the subject of procurement contracts. It consists of 9,454 codes structured in a five-level tree hierarchy. The first two digits we restrict attention to, identify the divisions.
} 
- CPV: IT products refers to office and computing machinery, equipment and supplies except furniture and software packages (CPV 30).

- CPV: intellectual services refers to business services (law, marketing, consulting, recruitment, printing and security) (CPV 79), IT services (consulting, software development, Internet and support) (CPV 72), administration, defence and social security services (CPV 75).

- CPV: transport products \& services refers to transport services (excl. waste transport) (CPV 60), supporting and auxiliary transport services, travel agencies services (CPV 63), transport equipment and auxiliary products to transportation (CPV 34).

- CPV-other refers to the other markets and is the reference category.

\section{Methodology}

For each analysis, we proceed in the same way.

1. First, we carry out a Logit analysis by integrating all the variables describing the contract, the department, its population, the Departmental Council and its political hue. Noting that correlation between social clause and environmental clause is 0.3183 , in each case we carry out two regressions, the first model testing the existence of clauses (social clause or environmental clause, regardless of the simultaneous presence of a clause of the other type), the second testing the existence of a clause of only one type (social clause only and environmental clause only).

The Hosmer-Lemeshow test is then used to determine the goodness of fit of the logistic regression models proposed. ${ }^{25}$

2. The presence of possible fixed effects (by Departmental Council) must be taken into account. Unfortunately, over the period considered, with the exception of contract-specific characteristics, the other parameters

\footnotetext{
${ }^{25}$ Essentially, it is a chi-square goodness of fit test where the data is divided into 10 equal subgroups. The null hypothesis is that the observed and expected probabilities of clauses are the same across all 10 percentile groups. A significant test result indicates that the model is not a good fit while a non-significant test cannot invalidate a good fit.
} 
in our dataset do not vary. Therefore, it is impossible to use a conditional Logit model. Nevertheless, to take this aspect into consideration, we performed 97 robustness check regressions, consisting of removing, for each of them, one department among all the departments in our data set. A coefficient that appears to be non significant for one of the 97 regressions may suggest some kind of fixed effect. This implies interpreting the results obtained with caution, keeping in mind that some effects may be explained by unobserved characteristics of the Departmental Councils.

3. Finally, insights are drawn from odds ratios on the selected explanatory variables.

\subsubsection{Test of the probability of having a social clause}

In France, social clauses in the overwhelming majority of cases take the form of so-called work-integration clauses. They may take the form of lots reserved for integration enterprises (set-aside social clauses): the right to participate in public procurement procedures is reserved to sheltered workshops and social economic operators active in social and occupational integration of disabled or disadvantaged persons. They may also take the form of a specific weighting assigned to integration efforts by the enterprise holding the contract (discriminatory rules). In French legislation (loi $\mathrm{n}^{\mathrm{o}} 2008-1249$, 1 December 2008), the work-integration sector can be defined as a sector enabling "unemployed people facing major social and/or occupational problems, to obtain employment contracts in order to facilitate their integration into the labor market"26 This is done via individual social and vocational training. The work-integration sector in France is structured with Work Integration Social Enterprises (WISE) that fall into four distinct categories: Intermediate Associations, Centres for Adaptation to Working Life, Integration Enterprises, and Temporary Work Integration Enterprises. Behind the national statistics on the use of social clauses there is a great deal of heterogeneity, as discussed in Section 4.1 .

Does this heterogeneity reflect compositional effects linked to the nature of the contracts awarded (which may be more or less favorable to the implementation of this type of clause) or heterogeneous preferences among public purchasers? In order to try to objectify the underlying explanatory factors,

\footnotetext{
${ }^{26}$ See e.g. Gianfaldoni and Morand 2015$]$.
} 
we test, through a Logit model, the different factors that could help explain the presence of a social clause in public contracts awarded by the various French Departmental Councils. Our regression results are presented in Table $4{ }^{27}$ As explained in 4.2 , we test the robustness of our results to the identity of the buyers (see Table 5).

Table 4: Regression Results

\begin{tabular}{|c|c|c|}
\hline & \multicolumn{2}{|c|}{ Dependent variable: } \\
\hline & Social clause & Social clause only \\
\hline CPV: agri. \& cleaning services - energy & $0.409(-0.083,0.902)$ & $0.622(-0.054,1.297)$ \\
\hline CPV: building \& construction & $1.558^{* * *}(1.228,1.887)$ & $1.806^{* * *}(1.341,2.271)$ \\
\hline CPV: IT products & $-0.221(-1.435,0.993)$ & $-13.965(-987.954,960.024)$ \\
\hline CPV: intellectual services & $0.364(-0.221,0.950)$ & $0.874^{* *}(0.146,1.602)$ \\
\hline CPV: transport products \& services & $0.432(-0.107,0.970)$ & $-0.063(-0.994,0.867)$ \\
\hline Inequalities & $0.139(-0.072,0.349)$ & $-0.066(-0.388,0.256)$ \\
\hline Solidarity Income Support & $0.421^{* * *}(0.182,0.660)$ & $0.624^{* * *}(0.267,0.981)$ \\
\hline Political Hue & $-0.657^{* * *}(-0.807,-0.507)$ & $-0.513^{* * *}(-0.716,-0.310)$ \\
\hline Chief Executive Gender & $-1.288^{* * *}(-1.885,-0.692)$ & $-2.062^{* * *}(-3.007,-1.116)$ \\
\hline Chief Executive Age & $-1.181^{* * *}(-1.459,-0.903)$ & $-1.964^{* * *}(-2.403,-1.525)$ \\
\hline Environmentalist Executive & $-0.874^{* * *}(-1.308,-0.439)$ & $-0.960^{* * *}(-1.532,-0.389)$ \\
\hline Constant & $-2.584^{* * *}(-3.205,-1.963)$ & $-3.451^{* * *}(-4.355,-2.547)$ \\
\hline Observations & 4,378 & 4,378 \\
\hline Log Likelihood & -742.260 & -453.876 \\
\hline Akaike Inf. Crit. & $1,508.521$ & 931.752 \\
\hline
\end{tabular}

Table 5: Possible fixed effects robustness check

\begin{tabular}{lcc}
\hline & \multicolumn{2}{c}{ Dependent variable: } \\
\cline { 2 - 3 } & Social clause & Social clause only \\
\hline (Intercept) & 0 & 0 \\
CPV: building \& construction & 0 & 0 \\
CPV: intellectual services & & 0.232 \\
Solidarity Income Support & 0.148 & 0.163 \\
Political Hue & 0 & 0.022 \\
Chief Executive Gender & 0.164 & 0.04 \\
Chief Executive Age & 0 & 0 \\
Environmentalist Executive & 0.034 & 0.977 \\
\hline \hline
\end{tabular}

\footnotetext{
${ }^{27}$ Throughout the paper, we report (on the same row as coefficients) regression results with 90 percent confidence intervals.
} 
We now focus on the six variables whose impact is significant. Before interpreting our results, we use the Hosmer-Lemeshow test to determine the goodness of fit of the logistic regression model proposed. As depicted by Table 6, with a p-value of .27 , we can reject the null hypothesis that the observed and expected probabilities of observing social clauses "only" are the same across all 10 percentile groups.

Table 6: Hosmer and Lemeshow test

\begin{tabular}{lcc}
\hline \hline & \multicolumn{2}{c}{ Dependent variable: } \\
\cline { 2 - 3 } & Social clause & Social clause only \\
\hline \hline X-squared & 9.7913 & 9.9391 \\
$\mathrm{df}$ & 8 & 8 \\
$\mathrm{p}$-value & 0.28 & 0.2693 \\
\hline \hline
\end{tabular}

In order to interpret our results, we now present, in Table 7, the odds ratios of significant variables.

Table 7: Odds Ratios

\begin{tabular}{lcc}
\hline \hline & \multicolumn{2}{c}{ Dependent variable: } \\
\cline { 2 - 3 } & Social clause & Social clause only \\
\hline CPV: building \& construction & $4.748(4.418,5.078)$ & $6.086(5.622,6.551)$ \\
CPV: intellectual services & $1.439(0.854,2.025)$ & $2.397(1.669,3.125)$ \\
Solidarity Income Support & $1.524(1.285,1.763)$ & $1.866(1.509,2.223)$ \\
Political Hue & $0.518(0.368,0.669)$ & $0.599(0.395,0.802)$ \\
Chief Executive Gender & $0.276(0.321,0.872)$ & $0.127(0.818,1.073)$ \\
Chief Executive Age & $0.307(0.029,0.585)$ & $0.140(-0.298,0.579)$ \\
Environmentalist Executive & $0.417(-0.017,0.852)$ & $0.383(-0.189,0.954)$ \\
Constant & $0.075(-0.545,0.696)$ & $0.032(-0.872,0.936)$ \\
\hline Observations & 4,378 & 4,378 \\
Log Likelihood & -742.260 & -453.876 \\
Akaike Inf. Crit. & $1,508.521$ & 931.752 \\
\hline \hline
\end{tabular}


- Let us firstly comment on the potential effects of population attributes. While the level of inequalities does not significantly explain the use of a social clause only, the percentage of inhabitants receiving the Solidarity Income Support does, and with a marked positive effect. Note also that this effect is more pronounced under the model testing the existence of a social clause only than under the model which allows for the potential coexistence of an environmental clause.

- Now focusing on contracts attributes, we see, from the odds ratio related to the type of contract (well above one for markets for building and construction as well as for intellectual services), presented in Table 7. that they significantly and markedly increase the probability of social clauses featuring in public procurement contracts. Obviously, markets for building and construction are, by their very nature, ideal supports for work integration clauses.

- Political attributes are also decisive in order to explain the use of social clauses. Left-wing Departmental Councils are thus more likely to include social clauses in their public procurement contracts. From Table 4 , we see that the probability of social clauses featuring in public procurement contracts decreases when an elected environmentalist on the Council has an executive function. The robustness test encourages caution (see table 5) in the interpretation of the latter. However, it could still indicate that the negative impact of the presence of an elected environmentalist on the Council may suggest a substituability between environmental and social objectives. Indeed, as we will see later, the presence of this environmentalist has a significant positive impact on the presence of environmental clauses only. Similarly, considering personal attributes of the chief executive, the probability of social clauses featuring in public procurement contracts decreases when she or he is older as well as when she is a female 28

According to our results, the use of social clauses seems to reflect the preferences of the median voter. Indeed, assuming that the social value of integration through work is more valuable in the departments with the

\footnotetext{
${ }^{28}$ The direction of the effect of the variables Chief Executive Gender, Chief Executive Age, and Environmentalist Executive is well established. However, given their odds ratios, the magnitude of this effect should be considered with caution since it cannot really be quantified.
} 
greatest number of persons who find it hard to integrate the labor market, our empirical analysis does not refute the hypothesis that social clauses reflect a high value associated with the social quality produced. Even if the robustness test of the Solidarity Income Support variable (see Table 5 ) encourages caution in the interpretation, this suggests that the use of social clauses partly reflects the benefit to the local authority of employing unemployed people facing substantial social and/or occupational problems and receiving otherwise a subsistence income paid by the Departmental Council. Using the terminology of our theoretical modeling, this can translate into a high level of endogenous "social quality" of the market fulfillment, $V\left(q_{i}\right)$, or high valuation of Work Integration Social Enterprises, $S_{i}$. In summary, our empirical model cannot refute the hypothesis that social clauses reflect strong (intrinsic or political) preferences for the provision of integration work.

\subsubsection{Test of the probability of having an environmental clause in a departmental public procurement contract}

Environmental clauses are more commonly used than social clauses in French public procurement contracts. In $2017,8.9 \%$ of contracts had environmental clauses, reflecting a change in this practice over time (it was only $5.0 \%$ in 2012), ${ }^{29}$ with this rate being relatively constant among the main types of public purchasers (with the exception of network operators who use substantially less). The overwhelming majority of these clauses take the form of an "environmental quality" criterion. Nevertheless, it is difficult to identify a priori whether the consideration of these criteria reflects a real environmental concern or whether, conversely, by making the comparison of offers less direct and transparent, they reflect a desire for favoritism. Conducting an approach similar to the previous model, but questioning the likelihood of having an environmental clause, one may expect the same type of results to occur. Surprisingly, our analysis will depict a significantly different story from the objectives underlying the use of environmental clauses.

For the analysis of environmental clauses, we proceed in a completely symmetrical way to the methodology carried out in the previous subsection. Our regression results are presented in Table 8 and the test of the robustness of our results to the identity of the buyers is depicted in Table 9 .

Note that, contrary to the previous analysis, the models that test for

\footnotetext{
${ }^{29} \mathrm{cf}$. Observatoire économique de l'achat public.
} 
Table 8: Regression Results

\begin{tabular}{|c|c|c|}
\hline & \multicolumn{2}{|c|}{ Dependent variable: } \\
\hline & Environmental clause & Environmental clause only \\
\hline CPV: agri. \& cleaning services - energy & $-0.487^{* *}(-0.880,-0.093)$ & $-0.709^{* *}(-1.183,-0.235)$ \\
\hline CPV: building \& construction & $0.513^{* * *}(0.282,0.744)$ & $0.229(-0.039,0.498)$ \\
\hline CPV: IT products & $0.900^{* * *}(0.405,1.396)$ & $0.977^{* * *}(0.446,1.508)$ \\
\hline CPV: intellectual services & $-0.293(-0.732,0.146)$ & $-0.266(-0.746,0.215)$ \\
\hline CPV: transport products \& services & $0.371^{*}(0.020,0.722)$ & $0.262(-0.146,0.670)$ \\
\hline Inequalities & $0.404^{* * *}(0.275,0.533)$ & $0.420^{* * *}(0.275,0.564)$ \\
\hline Solidarity Income Support & $-0.054(-0.241,0.134)$ & $-0.213(-0.458,0.031)$ \\
\hline Political Hue & $-0.254^{* * *}(-0.380,-0.127)$ & $0.027(-0.137,0.191)$ \\
\hline Chief Executive Gender & $-0.149(-0.518,0.220)$ & $-0.057(-0.480,0.365)$ \\
\hline Chief Executive Age & $-0.631^{* * *}(-0.849,-0.414)$ & $-0.725^{* * *}(-0.988,-0.462)$ \\
\hline Environmentalist Executive & $0.181(-0.175,0.538)$ & $0.689^{* * *}(0.253,1.125)$ \\
\hline Constant & $-2.446^{* * *}(-2.943,-1.950)$ & $-3.170^{* * *}(-3.806,-2.534)$ \\
\hline Observations & 4,378 & 4,378 \\
\hline Log Likelihood & $-1,106.734$ & -863.916 \\
\hline Akaike Inf. Crit. & $2,237.468$ & $1,751.832$ \\
\hline
\end{tabular}

Table 9: Possible fixed effects robustness check

\begin{tabular}{lll}
\hline \hline & \multicolumn{2}{c}{ Dependent variable: } \\
\cline { 2 - 3 } & Environmental clause & Environmental clause only \\
\hline (Intercept) & 0 & 0 \\
CPV: agri. \& cleaning services - energy & 0.100 & 0.040 \\
CPV: building \& construction & 0.005 & 0.486 \\
CPV: IT products & 0.017 & 0.018 \\
CPV: transport products \& services & 0.567 & 0.002 \\
Inequalities & 0.06 & \\
Political Hue & 0.981 & 0.006 \\
Chief Executive Age & 0.002 & 0.428 \\
Environmentalist Executive & &
\end{tabular}


the existence of an environmental clause and an environmental clause only offer a relatively different picture. Explanatory variables of a political nature (Political Hue and Environmentalist Executive) have a model-dependent significativeness. While Political Hue has a significant and negative impact in the model that tests for the existence of an environmental clause, it becomes a non-significant explanatory variable in the model that tests for the existence of an environmental clause only. The political effect is partly driven by the correlation between social clause and environmental clause. So, analyzing the model testing environmental clause only per se and its comparison with the model testing environmental clause allow us to better analyze this phenomenon.

In order to interpret our results, we summarize the odds ratios in Table 10.

Table 10: Odds Ratios

\begin{tabular}{lll}
\hline \hline & \multicolumn{2}{c}{ Dependent variable: } \\
\cline { 2 - 3 } & Environmental clause & Environmental clause only \\
\hline CPV: agri. \& cleaning services - energy & $0.615(0.221,1.008)$ & $0.492(0.018,0.966)$ \\
CPV: building \& construction & $1.670(1.439,1.901)$ & $1.258(0.989,1.526)$ \\
CPV: IT products & $2.460(1.965,2.956)$ & $2.657(2.126,3.187)$ \\
CPV: transport products \& services & $1.449(1.098,1.800)$ & $1.300(0.891,1.708)$ \\
Inequalities & $1.498(1.369,1.627)$ & $1.521(1.376,1.666)$ \\
Political Hue & $0.776(0.649,0.903)$ & $1.027(0.863,1.191)$ \\
Chief Executive Age & $0.532(0.314,0.750)$ & $0.484(0.221,0.747)$ \\
Environmentalist Executive & $1.199(0.842,1.555)$ & $1.992(1.557,2.428)$ \\
Constant & $0.087(-0.410,0.583)$ & $0.042(-0.594,0.678)$ \\
\hline Observations & 4,378 & 4,378 \\
Log Likelihood & $-1,106.734$ & -863.916 \\
Akaike Inf. Crit. & $2,237.468$ & $1,751.832$ \\
\hline \hline
\end{tabular}

- Let us first consider population attributes. Contrary to the social clauses model, the Solidarity Income Support covariate is not significant, while Inequalities is. This result is in line with intuition. Inhabitants receiving the Solidarity Income Support are the primary beneficiaries of the social clauses system, but this has nothing to do with preferences for environmental clauses. Conversely, relation between inequalities and environmental concern is well documented, even 
Table 11: Hosmer and Lemeshow test

\begin{tabular}{lcc}
\hline \hline & \multicolumn{2}{c}{ Dependent variable: } \\
\cline { 2 - 3 } & Environmental clause & Environmental clause only \\
\hline \hline X-squared & 7.4351 & 18.763 \\
$\mathrm{df}$ & 8 & 8 \\
$\mathrm{p}$-value & 0.4905 & 0.01618 \\
\hline \hline
\end{tabular}

if the direction of the relationship is an old and widely debated (see e.g. Boyce 1994 and Scruggs [1998]). The Inequalities odd ratio, presented in Table 10, suggests that a change in the category of the level of inequality measured by the 90/10 income ratio, significantly and markedly increases the probability of environmental clauses featuring in public procurement contracts. This result seems in line with Scruggs [1998] empirical results where the effect of inequality (measured by the GINI coefficient or the $80 / 20$ income ratio) on environmental quality is increasing. This may suggest that an increase of the inequality measure corresponds to an upward shift in median preferences, whereas "evidence indicates that better off members of society tend to have higher environmental concern than those with lower incomes".

- Now focusing on contracts attributes, we see, from Table10, that CPV: building \& construction is no longer significant in the model that tests for the existence of an environmental clause only. It remains significant in the model that tests for the existence of an environmental clause but this is due to the correlation between social clause and environmental clause. The covariate CPV: agri. \& cleaning services - energy appears significant and, somewhat counter-intuitively, it has a negative impact on the probability of having an environmental clause (and also an environmental clause only). Remark that, implicit in our modeling is the assumption that the type of market imposes itself on the purchaser. In a nutshell, the type of contract is considered only as the expression of a need, whereas the presence of a clause is considered as a choice. Alternatively, one could think that the type of contract is also a choice, which may reflect the Departmental Council preferences. Since our data set reflects only one year of public procurement, we are unfortunately not able to test this hypothesis. An 
analysis of the structure of purchases by Departmental Council over the long term would be necessary in order to identify such strategies.

- The political attributes deserve also some interesting comments. Although Political Hue is significant when testing the occurrence of a social clause, it is no longer significant for environmental clause only. These results suggest that environmental policy is not driven by the political hue but rather by individual concerns such as the age of the Chief (the older the Chief, the less the likelihood of an environmental clause only) or the presence of an environmental executive (who tends to increase environmental clauses to the detriment of social clauses). The impact of the individual characteristics of the chairs of departmental councils should certainly not be over-interpreted. They are primarily used to distinguish between what is a matter of partisan preferences and what is a matter of the more individual preferences of the chief executive. For environmental clause, the latter play a significant role, unlike the former. However, the presence of an environmental executive significantly increases the likelihood of an environmental clause only. This result is in line with what we observe in the relation between social clause and Environmentalist Executive. While the environmental policy objective appears to be substitute for the social objective, the impact of an elected environmentalist with executive function in the local government has a positive influence on the environmental policy. Beside, the environmental policy objective is consistent with the presence of environmental clauses in public procurement contracts. Even if the robustness test of Solidarity Income Support and Political Hue variables encourages caution in the interpretation, we can say that it is not a question of being left-wing or right-wing, but of incorporating an environmental objective into the public procurement policy being implemented.

Appendix A.5 presents a test of the probability of having simultaneously social and environmental clauses in a departmental public procurement contract. The results are consistent with the previous analyses. With an oddratio of respectively 0.467 and 0.494, Political Hue and Environmentalist Executive (see Table A17) are a good illustration of the possible relationship between the policy of clauses in public contracts and political preferences. The presence of an elected environmentalist with an executive function seems 
to have a positive impact only on purely environmental clauses: keeping all other variables constant, it is twice less likely to have simultaneously both types of clauses when an environmentalist co-chairs the Departmental Council. Besides, a shift to the right of the political hue of the Departmental Council also makes it twice less likely to observe simultaneously both types of clauses.

\subsubsection{How to tailor a contract to favor a firm?}

The previous analysis has shown that, on the one hand, from a theoretical point of view, several objectives could justify the use of S.E. clauses and that, on the other hand, from an empirical point of view, their use often seems to reveal objective priorities (political, local, or individual) and not necessarily a preference in the sense of favoritism linked to the identity of the firm. In order to explore this issue in greater depth, this subsection deals with this point in a manner complementary to the previous ones.

The analysis of the data from the 58,402 public contracts makes it possible to determine the identity of the selected companies. In particular, we can highlight the geographical proximity between buyers and suppliers. We will refer to local purchasing when the buyer's department is identical to the supplier's department. This local purchasing will be used as a proxy for favoritism.

Considering local purchasing as a proxy for favoritism is not so obvious. It is, however, a commonly shared view. As for example, Dimitri et al. 2006], in line with our analysis, consider that:

"More precise information can be an element favoring decentralized procurement. Local choices, however, might not always follow the "best value for money" principle. Sometimes decentralized selection of contractors can be less efficient than centralized selection since a local unit may be more inclined, than the centre, to favor local suppliers. Decentralized decisions may bring local suppliers closer to the buyer, and the potential for local lobbying activity to influence purchasing decisions can have a serious negative impact on procurement efficiency."

Note also that Saussier and Tirole 2015 establish the very connection between favoritism and local purchasing in their rationale for the recommen- 
dation of not entrusting the public procurement system with the task of achieving S.E. objectives:

"Taking into account various objectives increases the (ever-present) risk of favoritism. A public authority can, for example, place great importance on the implications in terms of local employment."

Based on the analysis of Hungarian public procurement data, and considering only the case of corruption practices, Fazekas and Wachs 2020] show that the amount of openness and clustering in public buyers' local contracting neighbourhood is predicted by the corruption risks index they provide. The authors also observe that corruption in both countries leads to exclusion in buyers' local markets.

\begin{tabular}{|c|c|c|c|}
\hline Public buyer (\%) & All contracts & Incl. env. clauses & Incl. soc. clauses \\
\hline local auth. & $\mathbf{6 6 . 2}$ & $\mathbf{6 9 . 0 3}$ & $\mathbf{6 8 . 7}$ \\
\hline public sector body & 42 & 30.2 & 50.9 \\
\hline national auth. & 65.4 & 53 & 63.7 \\
\hline region. agency & 51.2 & 24.9 & 3.6 \\
\hline nation. agency & 49.2 & 22.6 & 1. \\
\hline
\end{tabular}

Table 12: \% of local purchasing by buyer category

When analyzing the data by buyer's category in Table 12 , it is noteworthy that the share of local purchasing by local authorities appears to be greater when S.E. clauses are used (69\%) than when not (66\%). Conversely, for purchases by national public operators in the regions, the share of local purchasing is reduced when S.E. clauses are used.

\begin{tabular}{|c|c|c|c|}
\hline Procedure (\%) & All contracts & Incl. env. clauses & Incl. soc. clauses \\
\hline Open & 52.2 & 39.1 & 53.8 \\
\hline Negotiated & 64.8 & 71 & 61 \\
\hline Restricted & 76.6 & 59.9 & 96.7 \\
\hline Compet. with Negotiation & 76.4 & 84.1 & 85.6 \\
\hline Accelerated & 25.9 & 9.2 & 0 \\
\hline (Recall all) & $\mathbf{5 6 . 5}$ & $\mathbf{4 5 . 1}$ & $\mathbf{5 8 . 3}$ \\
\hline
\end{tabular}

Table 13: \% of local purchasing by procedure 
Now analyzing the frequency of local purchasing depending on the awarding procedure of the markets 30 Table 13 shows that $76 \%$ of Competitive Procedure with Negotiation procurement markets are awarded within the same region. However, this percentage becomes $84 \%$ if these markets include environmental clauses and $86 \%$ if they include social clauses. Thus, an econometric approach appears necessary to disentangle the specific impact of S.E. clauses in local purchasing. To be consistent with the previous sections, we will only focus on the public contracts awarded by the Departmental Councils. This choice also offers a coherent definition of our proxy: the political perimeter of the Departmental Councils is exactly the same as the one which defines the geographical scale of local purchasing (the department). Therefore, we test the hypothesis that it is in the buyer's interest to introduce S.E. clauses in order to favor a firm. More specifically, we test whether S.E. clauses are a more or less significant instrument than the use of specific technical and legal features of contracts. Indeed, reducing the advertising of contracts, choosing less restrictive procurement rules, allotting or not the contract are practices that a priori allow certain firms to be favored to the detriment of others. We consider here the probability of local purchasing as a proxy for favoritism. Obviously, local buying can be explained by many other reasonable reasons. However, our aim is not to distinguish between all these reasons but rather to determine whether S.E. clauses appear to be a key factor in order to help a local firm to succeed.

We use a Logit model where the probability of a local purchasing (local) may be influenced by

- The awarding procedure, where Open Procedure (the reference category), Accelerated Procedure, Negotiated Procedure, Competitive Procedure with negotiation, and Restricted Procedure are categorical variables standing for the type of procedure chosen.

- Publicity reflects the length of available publicity of the market (expressed in days)

- Allotment stands for allotted contracts and takes value 1 when the contract is allotted.

- Social clause (resp. Environmental clause) is a dummy variable

\footnotetext{
${ }^{30}$ See Appendix A.3 for more details relative to the procedural choices.
} 
that takes 1 if the contract incorporates a social (resp. environmental) clause.

The proposed regression is depicted in Table 14 and with a p-value of 0.77, the Hosmer and Lemeshow's goodness of fit test is satisfied. The odds ratio of significant variables are presented in Table 16

Table 14: Regression Results

\begin{tabular}{|c|c|}
\hline & Dependent variable: \\
\hline & local \\
\hline Allotment & $0.618^{* * *}(0.523,0.713)$ \\
\hline Publicity & $-0.512^{* * *}(-0.627,-0.396)$ \\
\hline Accelerated Procedure & $-0.249(-0.669,0.170)$ \\
\hline Negotiated Procedure & $-0.263(-0.601,0.075)$ \\
\hline Competitive Procedure with Negotiation & $0.555^{* * *}(0.453,0.658)$ \\
\hline Restricted Procedure & $-0.395(-1.281,0.491)$ \\
\hline Social clause & $-0.269^{* *}(-0.475,-0.064)$ \\
\hline Environmental clause & $-0.219^{* *}(-0.376,-0.061)$ \\
\hline Constant & $0.107(-0.047,0.261)$ \\
\hline Observations & 7,048 \\
\hline Log Likelihood & $-4,747.380$ \\
\hline Akaike Inf. Crit. & $9,512.760$ \\
\hline
\end{tabular}


Table 15: Hosmer and Lemeshow test

\begin{tabular}{|c|c|}
\hline \multicolumn{2}{|c|}{ Dependent variable: } \\
\hline & local \\
\hline X-squared & 4.8971 \\
\hline $\begin{array}{l}\text { df } \\
\text { p-value }\end{array}$ & $\begin{array}{c}8 \\
0.7685\end{array}$ \\
\hline
\end{tabular}

Table 16: Odds Ratios

\begin{tabular}{lc}
\hline \hline & Dependent variable: \\
\cline { 2 - 2 } & local \\
\hline Allotment & $1.855(1.760,1.950)$ \\
Publicity & $0.599(0.484,0.715)$ \\
Competitive Procedure with Negotiation & $1.743(1.640,1.846)$ \\
Social clause & $0.764(0.558,0.970)$ \\
Environmental clause & $0.804(0.646,0.961)$ \\
Constant & $1.113(0.959,1.267)$ \\
\hline Observations & 7,048 \\
Log Likelihood & $-4,747.380$ \\
Akaike Inf. Crit. & $9,512.760$ \\
\hline \hline
\end{tabular}


Two main lessons can be highlighted. First, while S.E. clauses have a significant impact on local purchasing, their impact is negative. Thus, public procurement contracts with S.E. clauses generate less local purchasing. Second, the other characteristics of the markets play in a direction that is in line with intuition. Indeed, increasing the duration of publicity reduces local purchasing, while choosing the competitive procedure with negotiation increases this probability. It is worth noting that the other procedures appear to be non-significant, as they are not very frequently present in our sample (see Table A10, Appendix A.4.

Of course, as the choice of procedures may strongly depend on the subject matter of the contract, potential fixed effects related to the latter should be controlled. A widespread reason that prevents the use of non-linear fixed effects models in practice is the so-called incidental parameter bias problem (IPP). So, we provide a post-estimation routine that applies the analytical bias correction derived by Fernández-Val [2009]. Table 17 presents the result of a Logit regression, where we control for unobserved subject matter heterogeneity considering the six contracts attributes depicted in Subsection 4.2 .

This analysis does not affect the general meaning of the results highlighted above. However, it should be noted that environmental clauses (while still negatively impacting the probability of local purchasing) are now a nonsignificant explanatory variable.

Our analysis thus seems to suggest that while the choice of precise public procurement procedure has a strong effect on local purchasing, it is not the S.E. clauses that are at issue. As depicted in Table 16, choosing a competitive procedure with negotiation increases the likelihood of local purchasing by $74 \%$ compared to an open procedure. Changing the advertising duration category reduces the likelihood of local purchasing by 1.67. Conversely, the presence of S.E. clauses reduces the likelihood of local purchasing by a factor of 1.31 and 1.24 respectively. Thus, if we accept the assumption that local purchasing is a good proxy for favoritism, our analysis does not suggest that S.E. clauses are used as an instrument for favoritism. 
Table 17: Subject matter fixed effects

\begin{tabular}{lcc}
\hline \hline & \multicolumn{2}{c}{ Dependent variable: } \\
\cline { 2 - 2 } & \multicolumn{2}{c}{ local } \\
\hline Allotment & $0.47^{* * *}$ & $(0.06)$ \\
Publicity & $-0.56^{* * *}$ & $(0.08)$ \\
Accelerated Procedure & -0.50 & $(0.27)$ \\
Negotiated Procedure & -0.01 & $(0.24)$ \\
Competitive Procedure with Negotiation & -0.41 & $(0.33)$ \\
Restricted Procedure & 0.05 & $(0.56)$ \\
Social clause & $-0.60^{* * *}$ & $(0.13)$ \\
Environmental clause & -0.14 & $(0.10)$ \\
\hline Log Likelihood & -4280.40 & \\
Deviance & 8560.80 & \\
Num. obs. & 7028 & \\
\hline \hline
\end{tabular}

${ }^{* * *} p<0.001 ;{ }^{* *} p<0.01 ;{ }^{*} p<0.05$

\section{Conclusion}

This article has highlighted the fact that S.E. clauses can be used as an optimal procurement policy. However, the mere observation of the use of clauses does not reveal the preferences of the public purchaser insofar as the theoretical analysis does not make it possible to disentangle precisely the reasons for the use of such clauses. Without accurate knowledge of the value that the public purchaser assigns to the profits of the firms, to the social surplus generated by the contract, to the (S.E.) quality supplied, the same award rule (whether in the form of a set-aside or a discriminatory rule) can implement the optimal policy in the sense of the optimal mechanism design. In addition, the practical rules observed diverge from the proper implementation of these procedures. Therefore, we have used an empirical analysis in order to identify the underlying objective function of the public buyer. By studying the public contracts awarded by the French Departmental Councils in 2017, we show the diversity of objectives that may justify such practices. While social clauses seem to reflect partisan preferences, this is 
not true for environmental clauses, which depend rather on the preferences of the local chief executive. Moreover, they seem to reflect more objective differences in the value assigned to the companies chosen or the economic performance achieved.

Then, using local purchasing as a proxy for favoritism, we have tested which legal characteristics of the contracts explain the local purchasing. In particular, we found that the inclusion of S.E. clauses significantly decreases the likelihood of local purchasing in public procurement. Thus, our analysis does not suggest that S.E. clauses are used as an instrument for favoritism. The risk of favoritism may rather be through the various methods of awarding markets and/or the a priori non-disclosure of detailed scoring rules, unfortunately not yet available for the data set mobilized in this study. ${ }^{31}$ Further work, retrospectively identifying legally contentious contracts, should make it possible to extend this analysis.

\section{A Appendix}

\section{A.1 Solving the optimal mechanism design problem}

The expected profit of firm $i$ is

$$
\Pi_{i}=\left(1-\gamma_{i}\right) t_{i}-c_{i}\left(q_{i}, \theta_{i}\right) x_{i} \Leftrightarrow t_{i}=\frac{c_{i}\left(q_{i}, \theta_{i}\right) x_{i}+\Pi_{i}}{1-\gamma_{i}} .
$$

Plugging the value of $t_{i}$ into (2) yields

$$
\begin{aligned}
\mathbb{E}_{\Theta} D S= & \int_{\Theta} \sum_{i}\left[\left(\hat{S}_{i}+\hat{V}\left(q_{i}\right)\right) x_{i}-\frac{1+\lambda-\gamma_{i}}{1-\gamma_{i}} c_{i}\left(q_{i}, \theta_{i}\right) x_{i}\right. \\
& \left.-\left(\frac{1+\lambda-\gamma_{i}}{1-\gamma_{i}}-\hat{\alpha}_{i}\right) \Pi_{i}\right] d F(\Theta) .
\end{aligned}
$$

When firm $i$ with efficiency parameter $\theta_{i}$ announces $\tilde{\theta}_{i}$, it makes a profit

$$
\Pi_{i}\left(\tilde{\theta}_{i}, \theta_{i}\right)=\left(1-\gamma_{i}\right) t_{i}\left(\tilde{\theta}_{i}, \theta_{-i}\right)-c_{i}\left(q_{i}, \theta_{i}\right) x_{i}\left(\tilde{\theta}_{i}, \theta_{-i}\right) .
$$

Incentive compatibility implies

$$
\left.\frac{d \prod_{i}}{d \tilde{\theta}_{i}}\right|_{\tilde{\theta}_{i}=\theta_{i}}=-c_{i_{\theta}}\left(q_{i}, \theta_{i}\right) x_{i}\left(\theta_{i}, \theta_{-i}\right),
$$

\footnotetext{
${ }^{31}$ For a detailed analysis of scoring rules, see e.g. Bergman and Lundberg 2013, Chen 2008, Mateus et al. 2010], and Telgen and Schotanus 2010.
} 
and by integration

$$
\int_{\theta_{i}}^{\bar{\theta}} \frac{d \Pi_{i}}{d \theta_{i}} d \theta_{i}=-\int_{\theta_{i}}^{\bar{\theta}} c_{i_{\theta}}\left(q_{i}, \theta_{i}\right) x_{i}\left(\theta_{i}, \theta_{-i}\right) d \theta_{i} .
$$

Then,

$$
\Pi_{i}=\int_{\theta_{i}}^{\bar{\theta}} c_{i_{\theta}}\left(q_{i}, \theta_{i}\right) x_{i}\left(\theta_{i}, \theta_{-i}\right) d \theta_{i}+\Pi_{i}(\bar{\theta}) .
$$

Substituting $\Pi_{i}$ in (A1) yields (3).

\section{A.2 Simulation}

In order to obtain Figure 1, we consider the following assumptions:

- $\gamma_{t}=\gamma_{s}=\gamma$ and $\gamma \sim \mathcal{U}[0,1]$

- $\theta_{i} \sim \mathcal{U}[0,1], i=t, s$

- $\alpha_{s}=\alpha_{t}=\alpha$ and $\alpha \sim \mathcal{U}[0,1]$

- $S_{s}=S_{1}$ and $S_{1} \sim \mathcal{U}[0,1]$

- For $S_{t}=S_{2}$ we successively consider

1. $S_{2} \sim \mathcal{U}[0,1]$

2. $S_{2} \sim \mathcal{U}[0,2]$

3. $S_{2} \sim \mathcal{U}[0,3]$

- $c\left(q_{i}, \theta_{i}\right)=\theta_{i} \forall q_{i}$

- $V\left(q_{i}\right)=0 \forall q_{i}$

The simulation was performed in Python by approximating the continuous distributions considering 20 possible realizations of each random variable respecting a uniform distribution. 


\section{A.3 Procedural choices}

- Choice of procedures. Following Directive 2014/24/EU on public procurement, when awarding public contracts, contracting authorities shall apply the national procedures adjusted to be in conformity with this Directive, provided that, without prejudice to Article 32, a call for competition has been published in accordance with this Directive. This allows:

- Open procedure: In open procedures, any interested economic operator may submit a tender in response to a call for competition.

- Restricted procedure: In restricted procedures, any economic operator may submit a request to participate in response to a call for competition by providing the information for qualitative selection that is requested by the contracting authority.

- Competitive procedure with negotiation: In competitive procedures with negotiation, any economic operator may submit a request to participate in response to a call for competition by providing the information for qualitative selection that is requested by the contracting authority.

- Competitive dialogue: In competitive dialogues, any economic operator may submit a request to participate in response to a contract notice by providing the information for qualitative selection that is requested by the contracting authority. Only those economic operators invited by the contracting authority may participate in the dialogue. Contracting authorities may limit the number of suitable candidates to be invited to participate in the procedure.

- Use of the negotiated procedure without prior publication: In specific cases and circumstances, Member States may provide that contracting authorities may award public contracts by a negotiated procedure without prior publication.

- Accelerated procedure: This is the same as the Open Procedure but with accelerated time-frames. This procedure can only be used in states of urgency.

- Allotment. Contracting authorities should be encouraged to divide large contracts into lots. Such division could be done on a quantitative 
basis or on a qualitative basis, in accordance with the different trades and specializations involved. The size and subject-matter of the lots should be determined freely by the contracting authority who should have a duty to consider the appropriateness of dividing contracts into lots while remaining free to decide autonomously on the basis of any reason it seems relevant, without being subject to administrative or judicial supervision. 


\section{A.4 Description of variables}

Table A1: Description of variables used in Subsections 4.2.1 and 4.2.2

\begin{tabular}{|c|c|c|}
\hline CPV & $\begin{array}{l}\text { classification system for public procurement describing } \\
\text { the subject of procurement contracts simap.ted.europa.eu/cpv }\end{array}$ & $\begin{array}{l}2 \text { digits } \\
\text { source: BOAMP }\end{array}$ \\
\hline CPV: agri. \& cleaning services - energy & {$[\mathrm{CPV}-09, \mathrm{CPV}-71, \mathrm{CPV}-90]$} & \\
\hline CPV: building \& construction & {$[\mathrm{CPV}-44, \mathrm{CPV}-45, \mathrm{CPV}-71]$} & \\
\hline CPV: IT products & [CPV-30] & \\
\hline CPV: intellectual services & [CPV-72, CPV-75, CPV-79] & \\
\hline CPV: transport products \& services & {$[\mathrm{CPV}-60, \mathrm{CPV}-63, \mathrm{CPV}-34]$} & \\
\hline Inequalities & $\begin{array}{l}\text { level of inequality ratio } \\
{[2.6,3.38](3.38,4.16](4.16,4.94](4.94,5.72](5.72,6.5]}\end{array}$ & $\begin{array}{l}\text { source: INSEE } \\
\text { D90/D10 }\end{array}$ \\
\hline Solidarity Income Support & $\begin{array}{l}\text { inhabitants receiving the Solidarity Income Support (R.S.A.) } \\
{[1.93,6.42](6.42,10.9](10.9,15.4](15.4,19.9](19.9,24.4]}\end{array}$ & source: INSEE \\
\hline Political Hue $=3$ & right party at the head of the Departmental Council & source: RNE \\
\hline Political Hue $=2$ & center-right party at the head of the Departmental Council & source: RNE \\
\hline Political Hue $=1$ & Socialist Party at the head of the Departmental Council & source: RNE \\
\hline Political Hue $=0$ & far-left party at the head of the Departmental Council & source: RNE \\
\hline Environmentalist Executive & $\begin{array}{l}1 \text { if an elected environmentalist on the Council } \\
\text { has an executive function (vice-chair of the Council or task officer) }\end{array}$ & source: RNE \\
\hline Chief Executive Gender & 1 if a woman chairs the Departmental Council, 0 otherwise & source: RNE \\
\hline Chief Executive Age & $\begin{array}{l}\text { age of the person who chairs the departemental council } \\
{[31,62](62,76]}\end{array}$ & $\begin{array}{l}\text { source: RNE } \\
\text { years }\end{array}$ \\
\hline Social clause & 1 if the contract includes a social clause, 0 otherwise & source: BOAMP \\
\hline Environmental clause & 1 if the contract includes an environmental clause, 0 otherwise & source: BOAMP \\
\hline
\end{tabular}

Table A2: Description of variables used in Subsection 4.2.3

\begin{tabular}{lll}
\hline \hline Allotment & $\begin{array}{l}1 \text { if the market is allotted, 0 otherwise } \\
\text { duration of the tender advertisement in days }\end{array}$ & source: BOAMP \\
Publicity & {$[4,76.2](76.2,148](148,221](221,293](293,365]$} & source: BOAMP \\
& categorical variable & source: BOAMP \\
Open Procedure & categorical variable & source: BOAMP \\
Accelerated Procedure & categorical variable & source: BOAMP \\
Negotiated Procedure & categorical variable & source: BOAMP \\
Competitive Procedure with Negotiation & categorial variable & source: BOAMP \\
Restricted Procedure & 1 if the contract includes a social clause, 0 otherwise & source: BOAMP \\
Social clause & 1 if the contract includes an environmental clause, 0 otherwise & source: BOAMP \\
Environmental clause & 1 if NUTS supplier = NUTS purchaser & source: BOAMP \\
local &
\end{tabular}


Table A3: Descriptive statistics of variables used in Subsections 4.2.1 and 4.2 .2

\begin{tabular}{lcccccc}
\hline \hline Statistic & Mean & s.d. & Median & Min & Max & $\mathrm{n}$ \\
\hline \hline Social clause & 0.05 & 0.21 & 0 & 0 & 1 & 4378 \\
Environmental clause & 0.07 & 0.26 & 0 & 0 & 1 & 4378 \\
Inequalities & 1.48 & 0.73 & 1 & 1 & 5 & 4378 \\
(Inequalities) & 3.34 & 0.5 & 3.2 & 2.6 & 6.5 & 4378 \\
Solidarity Income Support & 1.31 & 0.59 & 1 & 1 & 5 & 4378 \\
(Solidarity Income Support) & 5.54 & 2.74 & 4.93 & 1.93 & 24.39 & 4378 \\
Political Hue & 2.32 & 0.91 & 3 & 0 & 3 & 4378 \\
Environmentalist Executive & 0.07 & 0.26 & 0 & 0 & 1 & 4378 \\
Chief Executive Gender & 0.09 & 0.28 & 0 & 0 & 1 & 4378 \\
Chief Executive Age & 0.47 & 0.5 & 0 & 0 & 1 & 4378 \\
(Chief Executive Age) & 59.41 & 9.45 & 60 & 31 & 76 & 4378 \\
\hline \hline
\end{tabular}

Note: (.) stands for the variables before recoding

Table A4: Contracts attributes: CPV

\begin{tabular}{lccc}
\hline \hline CPV: & others & building \& construction & agri. \& cleaning services - energy \\
\hline \hline Count & 1477.00 & 1463.00 & 584.00 \\
Percent & 33.74 & 33.42 & 13.34 \\
\hline \hline & transport products \& services & intellectual services & IT products \& services \\
\hline \hline & 390.00 & 354.00 & 110.00 \\
& 8.91 & 8.09 & 2.51 \\
\hline \hline
\end{tabular}

Table A5: Social clauses by political hue

\begin{tabular}{lccccc}
\hline \hline Social clause & pol.hue & 0 & 1 & 2 & 3 \\
\hline \hline 0 & & & & & \\
1 & 38 & 1113 & 409 & 2610 \\
& 0 & 111 & 9 & 88 \\
\hline \hline
\end{tabular}


Table A6: Environmental clauses by political hue

\begin{tabular}{lccccc}
\hline \hline & Political Hue & 0 & 1 & 2 & 3 \\
\hline Environmental clause & & & & & \\
\hline \hline 0 & 36 & 1102 & 386 & 2530 \\
1 & 2 & 122 & 32 & 168 \\
\hline \hline
\end{tabular}

Table A7: Social clauses by CPV

\begin{tabular}{lccr}
\hline \hline Social clause / CPV & CPV-others & CPV: agri. \& cleaning services - energy & CPV: building \& construction \\
\hline \hline 0 & 1443 & 566 & 1334 \\
1 & 34 & 18 & 129 \\
\hline \hline & CPV: IT products & CPV: intellectual services & CPV: transport products \& services \\
\hline \hline 0 & 108 & 343 & 376 \\
1 & 2 & 11 & 14 \\
\hline \hline
\end{tabular}

Table A8: Environemntal clauses by CPV

\begin{tabular}{lccc}
\hline \hline Environmental clause / CPV & CPV-others & CPV: agri. \& cleaning services - energy & CPV: building \& construction \\
\hline \hline 0 & 1382 & 561 & 1323 \\
1 & 95 & 23 & 140 \\
\hline \hline & CPV: IT products & CPV: intellectual services & CPV: transport products \& services \\
\hline \hline 0 & 95 & 336 & 357 \\
1 & 15 & 18 & 33 \\
\hline \hline
\end{tabular}

Table A9: Descriptive statistics of variables used in Subsection 4.2 .3

\begin{tabular}{lcccccc}
\hline \hline Statistic & Mean & s.d. & Median & Min & Max & $\mathrm{n}$ \\
\hline \hline (Allotment) & 9.04 & 15.55 & 4 & 1 & 126 & 58402 \\
Allotment & 0.75 & 0.43 & 1 & 0 & 1 & 7048 \\
(Publicity) & 47.59 & 36.28 & 45 & 4 & 365 & 58181 \\
Publicity & 1.11 & 0.37 & 1 & 1 & 5 & 7048 \\
Social clause & 0.04 & 0.2 & 0 & 0 & 1 & 7048 \\
Environmental clause & 0.08 & 0.26 & 0 & 0 & 1 & 7048 \\
local & 0.52 & 0.5 & 1 & 0 & 1 & 7048 \\
\hline \hline
\end{tabular}

Note: $\quad$ (.) stands for the variables before recoding 
Table A10: Procurement procedure

\begin{tabular}{lccccc}
\hline \hline procedure: & Open & Compet. with Negotiation & Negotiated & Restricted & Accelerated \\
\hline \hline Count & 5404 & 1457 & 104 & 66 & 17 \\
Percent & 76.67 & 20.67 & 1.48 & 0.94 & 0.24 \\
\hline \hline
\end{tabular}

Table A11: Local purchasing by procurement procedure

\begin{tabular}{lcccccc}
\hline \hline local & Procedure: & Accelerated & Negotiated & Compet. with Nego. & Restricted & Open \\
\hline \hline 0 & 39 & 62 & 552 & 12 & 2714 \\
1 & 27 & 42 & 905 & 5 & 2690 \\
\hline \hline
\end{tabular}

Table A12: Local purchasing by social clauses

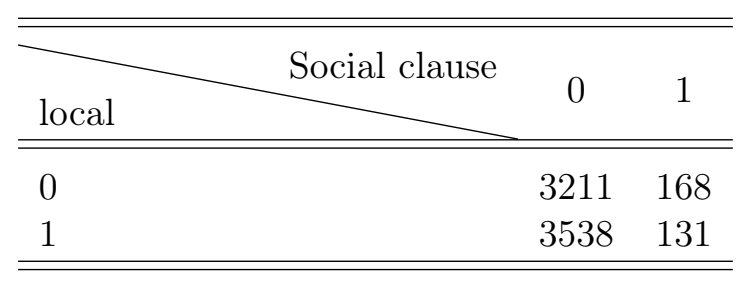

Table A13: Local purchasing by environmental clauses

\begin{tabular}{|c|c|c|c|}
\hline local & Environmental clause & 0 & 1 \\
\hline 0 & & 3087 & 292 \\
\hline 1 & & 3432 & 237 \\
\hline
\end{tabular}

Table A14: Local purchasing by publicity length

\begin{tabular}{lcccccc}
\hline \hline & Publicity & {$[4,76.2]$} & $(76.2,148]$ & $(148,221]$ & $(221,293]$ & $(293,365]$ \\
\hline \hline 0 & & 2964 & 341 & 69 & 3 & 2 \\
1 & 3418 & 216 & 35 & 0 & 0 \\
\hline \hline
\end{tabular}




\section{A.5 Test of the probability of having simultaneously a social and an environmental clause in a departmen- tal public procurement contract}

Table A15: Regression Results

\begin{tabular}{|c|c|}
\hline & Dependent variable: \\
\hline & Environmental clause \& Social clause \\
\hline CPV: agri. \& cleaning services - energy & $0.166(-0.542,0.873)$ \\
\hline CPV: building \& construction & $1.191^{* * *}(0.733,1.649)$ \\
\hline CPV: IT products & $0.442(-0.802,1.686)$ \\
\hline CPV: intellectual services & $-0.372(-1.406,0.662)$ \\
\hline CPV: transport products \& services & $0.718^{*}(0.056,1.380)$ \\
\hline Inequalities & $0.273^{*}(0.004,0.542)$ \\
\hline Solidarity Income Support & $0.245(-0.053,0.543)$ \\
\hline Political Hue & $-0.761^{* * *}(-0.975,-0.547)$ \\
\hline Chief Executive Gender & $-0.512(-1.253,0.228)$ \\
\hline Chief Executive Age & $-0.351(-0.728,0.026)$ \\
\hline Environmentalist Executive & $-0.705^{*}(-1.333,-0.077)$ \\
\hline Constant & $-3.371^{* * *}(-4.201,-2.540)$ \\
\hline Observations & 4,378 \\
\hline Log Likelihood & -414.425 \\
\hline Akaike Inf. Crit. & 852.850 \\
\hline Note: & ${ }^{*} \mathrm{p}<0.1 ;{ }^{* *} \mathrm{p}<0.05 ;{ }^{* * *} \mathrm{p}<0.01$ \\
\hline
\end{tabular}

Table A16: Hosmer and Lemeshow test

\begin{tabular}{lc}
\hline \hline & \multicolumn{2}{c}{ Dependent variable: } \\
& Environmental clause \& Social clause \\
\hline \hline X-squared & 9.1522 \\
$\mathrm{df}$ & 8 \\
$\mathrm{p}$-value & 0.3296 \\
\hline \hline
\end{tabular}


Table A17: Odds Ratios

\begin{tabular}{lc}
\hline \hline & Dependent variable: \\
\cline { 2 - 2 } & Environmental clause \& Social clause \\
\hline CPV: building \& construction & $3.291(2.832,3.749)$ \\
CPV: transport products \& services & $2.051(1.388,2.713)$ \\
Inequalities & $1.314(1.045,1.583)$ \\
Political Hue & $0.467(0.253,0.681)$ \\
Environmentalist Executive & $0.494(-0.134,1.122)$ \\
Constant & $0.034(-0.796,0.865)$ \\
\hline Observations & 4,378 \\
Log Likelihood & -414.425 \\
Akaike Inf. Crit. & 852.850 \\
\hline \hline
\end{tabular}

Table A18: Possible fixed effects robustness check

\begin{tabular}{lc}
\hline \hline & \multicolumn{1}{c}{ Dependent variable: } \\
\cline { 2 - 2 } & Environmental clause \& Social clause \\
\hline (Intercept) & 0 \\
CPV: building \& construction & 0 \\
CPV: transport products \& services & 0.450 \\
Inequalities & 0.168 \\
Political Hue & 0 \\
Environmentalist Executive & 0.290 \\
\hline \hline
\end{tabular}




\section{References}

Aidt, T. S. (2003). Economic analysis of corruption: a survey. The Economic Journal, 113(491):F632-F652.

Aidt, T. S. (2016). Rent seeking and the economics of corruption. Constitutional Political Economy, 27(2):142-157.

Albano, G. L., Cesi, B., and Iozzi, A. (2017). Public procurement with unverifiable quality: The case for discriminatory competitive procedures. Journal of Public Economics, 145:14-26.

Asker, J. and Cantillon, E. (2008). Properties of scoring auctions. The Rand Journal of Economics, 39(1):69-85.

Asker, J. and Cantillon, E. (2010). Procurement when price and quality matter. The Rand journal of economics, 41(1):1-34.

Bergman, M. A. and Lundberg, S. (2013). Tender evaluation and supplier selection methods in public procurement. Journal of Purchasing and Supply Management, 19(2):73-83.

Boyce, J. K. (1994). Inequality as a cause of environmental degradation. Ecological economics, 11(3):169-178.

Branco, F. (1994). Favoring domestic firms in procurement contracts. Journal of International Economics, 37(1-2):65-80.

Briquet, J.-L. (2020). Les liens entre clientélisme et corruption. Revue francaise d'administration publique, 175(3):629-644.

Burguet, R. and Che, Y.-K. (2004). Competitive procurement with corruption. RAND Journal of Economics, pages 50-68.

Celentani, M. and Ganuza, J.-J. (2002). Corruption and competition in procurement. European Economic Review, 46(7):1273-1303.

Che, Y.-K. (1993). Design competition through multidimensional auctions. The RAND Journal of Economics, pages 668-680.

Chen, T. H. (2008). An economic approach to public procurement. Journal of public procurement, 8(3):407-430. 
Cheng, W., Appolloni, A., D'Amato, A., and Zhu, Q. (2018). Green public procurement, missing concepts and future trends-a critical review. Journal of Cleaner Production, 176:770-784.

Dastidar, K. G. and Mukherjee, D. (2014). Corruption in delegated public procurement auctions. European Journal of Political Economy, 35:122127.

Denny-Smith, G., Williams, M., and Loosemore, M. (2020). Assessing the impact of social procurement policies for indigenous people. Construction Management and Economics, 38(12):1139-1157.

Dimitri, N., Dini, F., and Piga, G. (2006). When should procurement be centralized. Handbook of procurement, pages 47-81.

Fazekas, M. and Wachs, J. (2020). Corruption and the network structure of public contracting markets across government change. Politics and Governance, 8(2):153-166.

Fernández-Val, I. (2009). Fixed effects estimation of structural parameters and marginal effects in panel probit models. Journal of Econometrics, 150(1):71-85.

Gianfaldoni, P. and Morand, P.-H. (2015). Incentives, procurement and regulation of work integration social enterprises in france: old ideas for new firms? Annals of Public and Cooperative Economics, 86(2):199-219.

Hessami, Z. (2014). Political corruption, public procurement, and budget composition: Theory and evidence from oecd countries. European Journal of political economy, 34:372-389.

Laffont, J.-J. and Tirole, J. (1991). Auction design and favoritism. International Journal of Industrial Organization, 9(1):9-42.

Lambsdorff, J. G. (2002). Corruption and rent-seeking. Public choice, 113(1):97-125.

Lindström, H., Lundberg, S., and Marklund, P.-O. (2020). How green public procurement can drive conversion of farmland: An empirical analysis of an organic food policy. Ecological Economics, 172:106622. 
Lundberg, S. and Marklund, P.-O. (2013). Green public procurement as an environmental policy instrument: cost effectiveness. Environmental Economics, 4(4):75-83.

Lundberg, S., Marklund, P.-O., and Strömbäck, E. (2012). Objective effectiveness of green public procurement'. In 5th International Public Procurement Conference, Seattle, Washington, pages 15-17. Citeseer.

Lundberg, S., Marklund, P.-O., and Strömbäck, E. (2016). Is environmental policy by public procurement effective? Public Finance Review, 44(4):478499.

Manelli, A. M. and Vincent, D. R. (1995). Optimal procurement mechanisms. Econometrica: Journal of the Econometric Society, pages 591-620.

Marron, D. B. (1997). Buying green: Government procurement as an instrument of environmental policy. Public Finance Review, 25(3):285-305.

Mateus, R., Ferreira, J., and Carreira, J. (2010). Full disclosure of tender evaluation models: Background and application in portuguese public procurement. Journal of Purchasing and Supply Management, 16(3):206-215.

McAfee, R. P. and McMillan, J. (1989). Government procurement and international trade. Journal of international economics, 26(3-4):291-308.

McCrudden, C. (2007). Buying social justice: Equality, government procurement, \& legal change. Oxford University Press on Demand.

Morand, P.-H. (2003). Smes and public procurement policy. Review of Economic Design, 8(3):301-318.

Morand, P.-H. (2021). Replication files for "are social and environmental clauses a tool for favoritism?". Zenodo, DOI:10.5281/zenodo.5576206.

Myerson, R. B. (1981). Optimal auction design. Mathematics of operations research, 6(1):58-73.

Naegelen, F. and Mougeot, M. (1998). Discriminatory public procurement policy and cost reduction incentives. Journal of Public Economics, 67(3):349-367. 
Nishimura, T. (2015). Optimal design of scoring auctions with multidimensional quality. Review of Economic Design, 19(2):117-143.

Saussier, S. and Tirole, J. (2015). Strengthening the efficiency of public procurement. Notes du conseil d?analyse économique, 3:1-12.

Saussier, S. and Vidal, L. (2021). The cost of social public procurement for governments the case of paris city. Working paper, Sorbonne Business School.

Scruggs, L. A. (1998). Political and economic inequality and the environment. Ecological Economics, 26(3):259 - 275.

Sinclair-Desgagné, B. (1990). On the regulation of procurement bids. Economics Letters, 33(3):229-232.

Telgen, J. and Schotanus, F. (2010). The effects of full transparency in supplier selection on subjectivity and bid quality. In Proceedings of the Fourth International Public Procurement Conference.

Vagstad, S. (1995). Promoting fair competition in public procurement. Journal of Public Economics, 58(2):283-307. 